\title{
AN INTERPRETATION OF MULTI-MODEL FUTURE CLIMATE PREDICTIONS FOR BIOCLIM VARIABLES IN ROMANIA
}

\author{
Ilie-Adrian STOICA ${ }^{1}$ \\ ${ }^{1}$ Department of Taxonomy and Ecology, Institute of Biological Research, RO-400015 Cluj-Napoca, Romania \\ e-mail: adrian.stoica@icbcluj.ro
}

\begin{abstract}
Climate change is one of the biggest challenges of our century. As many climate models exist for the Romanian territory, each simulating a number of possible future scenarios for the emission of greenhouse gases, it is difficult to summarize the predicted impacts. This paper analyzes the output of a part of the Worldclim dataset, namely the 19 bioclim variables for 11 General Circulation Models, 4 RCP (Representative Concentration Pathway) scenarios and 2 years $(2050,2070)$ at 5 arc minutes $(\sim 10 \mathrm{~km})$. These 19 variables were conceived to be relevant for species physiology across phyla, and are extensively used in current literature for species distribution modelling. In order to make informed choices in the fitting of models (simulations of future niche changes), an interpretation is needed for the future variation of each bioclim variable and each combination of GCM, year and greenhouse gas emission scenario (RCP). While GCM rankings are different for each variable and each year-RCP combination, some general characteristics can be derived for each GCM. For the Romanian territory, the $h d$ model (HadGEM2$\mathrm{AO}$ ) can be considered overall as a pessimistic model in relation to temperature and precipitation variables (high temperature increase, high precipitation decrease). The $m g$ GCM (MRI-CGCM3) can be regarded as an optimistic model in relation to predicted temperature increase (less warming), but also in relation to precipitation (higher rainfall). The $m i$ (MIROC-ESM-CHEM) also usually predicts a more humid future in Romania, but with higher temperature increase. The ip GCM (IPSL-CM5A-LR) predicts the highest increase in temperatures during cold months in Romania, as well as drier winters and less temperature variability (monthly and yearly). A moderate model for our country is $c c$ (CCSM4), which can be used as a balanced model (it is optimistic only for cold season temperatures, predicting the lowest increase). Overall, for temperature variables there is a general consensus (increase of temperatures for all combinations of GCM, RCP and year). Regarding precipitations the trends are not very clear. An exception is probably the RCP85 scenario, which causes most GCMs to predict a decrease in precipitation variables, but even for this scenario there are models indicating an increase.
\end{abstract}

Keywords: climate change, general circulation models comparison, worldclim, bioclim, climate of Romania, variables for species distribution modelling

\section{Introduction}

Climate change is a major threat to mankind, with potential impacts manifesting on numerous domains, ranging from agriculture and biodiversity to water accessibility, risk management and human migration [8].

Climate is generally difficult to simulate, as multiple factors play a role in its genesis: Earth axis tilt, distance from the Sun, position of the Earth on the ellipse around the Sun, solar activity, solar radiation received on Earth - short waves and long waves, convection, albedo, cloud cover, ocean currents, surface air pressure, elevation of above-ground landforms, dominant wind direction. Using historical weather data and parameters such as those mentioned above, several meteorological laboratories around the world have attempted to simulate the Earth's air flow circulation, essential in the determination of climate. Such models are usually named 
General Circulation Models (GCMs).

Aside from the physical and geographical variables required to parameterize such models, an important component is represented by the chemical composition of the atmosphere. Among the gases present in the atmosphere, some of the most important that play a role in the determination of climate are greenhouse gases. According to the $5^{\text {th }}$ Assessment Report (AR5) redacted by the IPCC (Intergovernmental Panel on Climate Change), four Representative Concentration Pathways (RCP) are agreed upon as scenarios of future emissions of greenhouse gases. These RCPs have been labelled after the range of radiative forcing values in the year 2100 (compared to the pre-industrial values): $+2.6,+4.5,+6.0,+8.5 \mathrm{~W} / \mathrm{m}^{2}: \mathrm{RCP} 2.6$ (or RCP26), RCP 4.5 (or RCP45), RCP 6.0 (or RCP60), RCP 8.5 (or RCP85).

Climate simulations have been provided by several meteorological offices around the world. Among the sources of climatic data used to infer climate change related impacts on biodiversity, the Worldclim dataset [2] is one of the most used. Version 1.4 of this climate dataset includes simulations made for the WCRP (World Climate Research Programme) Coupled Model Intercomparison, Phase 5 (CMIP5). The Worldclim dataset contains the output of 19 General Circulation Models (GCM), with the 4 greenhouse gases emission scenarios (RCPs) for 2 years (2050 and 2070) at 4 resolutions ( 10 minutes - about $20 \mathrm{~km}$ at $45^{0} \mathrm{~N}, 5$ minutes - about $10 \mathrm{~km}$ at $45^{\circ} \mathrm{N}, 2.5$ minutes - about $5 \mathrm{~km}$ at $45^{\circ} \mathrm{N}$ and 30 seconds - about $1 \mathrm{~km}$ at $45^{\circ} \mathrm{N}$ ). Of these 19 GCMs, 11 have complete RCP simulations (all four greenhouse gases emissions scenarios have been calculated). The WCRP Coupled Model Intercomparison Project, Phase 5 (CMIP5), was a global climate model intercomparison project, coordinated by PCMDI (Program For Climate Model Diagnosis and Intercomparison) on behalf of the World Climate Research Program (WCRP) and provided input for the IPCCs 5th Assessment Report (AR5).

Table 1: General Circulation Models (GCMs) used from the Worldclim database [2]

\begin{tabular}{|c|c|c|c|c|}
\hline No. & Name & Country & Short & Code \\
\hline 1 & Beijing Climate Center Climate System Model & China & $b c$ & BCC-CSM1-1 \\
\hline 2 & Community Climate System Model & USA & $c c$ & CCSM4 \\
\hline 3 & Goddard Institute for Space Studies & USA & gs & GISS-E2-R \\
\hline 4 & $\begin{array}{l}\text { National Institute of Meteorological Research and } \\
\text { Korean National Institute of Meteorological } \\
\text { Research }\end{array}$ & Korea & $h d$ & HadGEM2-AO \\
\hline 5 & Met Office Hadley Center Earth System Model & UK & he & HadGEM2-ES \\
\hline 6 & $\begin{array}{l}\text { Institute Pierre Simon Laplace - Climate Modelling } \\
\text { Center (Low Resolution) }\end{array}$ & France & ip & IPSL-CM5A-LR \\
\hline 7 & $\begin{array}{l}\text { Japan Agency for Marine-Earth Science and } \\
\text { Technology - Model for Interdisciplinary Research } \\
\text { on Climate - Earth System Model - Atmospheric } \\
\text { Chemistry }\end{array}$ & Japan & $m i$ & $\begin{array}{l}\text { MIROC-ESM- } \\
\text { CHEM }\end{array}$ \\
\hline 8 & $\begin{array}{l}\text { Japan Agency for Marine-Earth Science and } \\
\text { Technology - Model for Interdisciplinary Research } \\
\text { on Climate }\end{array}$ & Japan & $m r$ & MIROC-ESM \\
\hline 9 & $\begin{array}{l}\text { Japan Agency for Marine-Earth Science and } \\
\text { Technology - Model for Interdisciplinary Research } \\
\text { on Climate }\end{array}$ & Japan & $m c$ & MIROC5 \\
\hline 10 & Japan Meteorological Research Institute & Japan & $m g$ & MRI-CGCM3 \\
\hline 11 & Norwegian Earth System Model & Norway & no & NorESM1-M \\
\hline
\end{tabular}


In the Worldclim dataset [2], for each RCP simulation, aside from the monthly forecast data (precipitations, minimum and maximum temperatures), a total of 19 bioclimatic variables have been calculated (11 temperature-based, and 8 precipitation-based). These variables have been generated based on their biological significance, with the intention to help scientists generate better species distribution models, and assess the variation of the species niche with the changing climate [5-7, 11, 12].

An analysis of the potential climate change throughout the Romanian territory predicted by each GCM for these biologically meaningful variables is currently missing, affecting the ability to interpret any results (i.e. predicted future species niches). Adding to the problem, there is a large number of possible future combinations for each variable (11 GCMs, 4 RCPs, 2 years). Model (GCM) uncertainty is recognized as a problem, adding to climate (RCP) uncertainty [4], so a comprehensive study is needed to take all possible futures into account.

Table 2: Bioclim variables [6]

\begin{tabular}{lll}
\hline Shortcut & Name of variable & Units \\
\hline BIO1 & Annual Mean Temperature & ${ }^{\circ} \mathrm{C} \times 10$ \\
BIO2 & Mean Diurnal Range (Mean of monthly (max temp - min temp)) & ${ }^{\circ} \mathrm{C} \times 10$ \\
BIO3 & Isothermality (BIO2/BIO7) $(* 100)$ & $\%$ (percent) \\
BIO4 & Temperature Seasonality (standard deviation *100) & ${ }^{\circ} \mathrm{C} \times 1000$ \\
BIO5 & Max Temperature of Warmest Month & ${ }^{\circ} \mathrm{C} \times 10$ \\
BIO6 & Min Temperature of Coldest Month & ${ }^{\circ} \mathrm{C} \times 10$ \\
BIO7 & Temperature Annual Range (BIO5-BIO6) & ${ }^{\circ} \mathrm{C} \times 10$ \\
BIO8 & Mean Temperature of Wettest Quarter & ${ }^{\circ} \mathrm{C} \times 10$ \\
BIO9 & Mean Temperature of Driest Quarter & ${ }^{\circ} \mathrm{C} \times 10$ \\
BIO10 & Mean Temperature of Warmest Quarter & ${ }^{\circ} \mathrm{C} \times 10$ \\
BIO11 & Mean Temperature of Coldest Quarter & ${ }^{\circ} \mathrm{C} \times 10$ \\
BIO12 & Annual Precipitation & $\mathrm{mm}$ \\
BIO13 & Precipitation of Wettest Month & $\mathrm{mm}$ \\
BIO14 & Precipitation of Driest Month & $\mathrm{mm}$ \\
BIO15 & Precipitation Seasonality (Coefficient of Variation) & ${ }^{\%}$ (percent) \\
BIO16 & Precipitation of Wettest Quarter & $\mathrm{mm}$ \\
BIO17 & Precipitation of Driest Quarter & $\mathrm{mm}$ \\
BIO18 & Precipitation of Warmest Quarter & $\mathrm{mm}$ \\
BIO19 & Precipitation of Coldest Quarter & $\mathrm{mm}$ \\
\hline
\end{tabular}

\section{Material and Methods}

The 11 GCMs of the Worldclim dataset that have all RCP scenarios generated $(26,45,60,85)$ have been taken into consideration (Tab. 1). For each of these GCMs, we have considered all 19 bioclim variables (Tab. 2). For faster processing of the data, the 5 minute resolution version of these datasets was selected for processing (approximately $10 \mathrm{~km}$ resolution at $45^{\circ}$ latitude $\mathrm{N}$ ), assuming that the large-scale trends are valid at all resolutions.

The bioclim variables capture information about:

- annual means (BIO1 - Annual Mean Temperature, BIO12 - Annual Precipitation),

- seasonal means (BIO8 - Mean Temperature of Wettest Quarter, BIO9 - Mean 
Temperature of Driest Quarter, BIO10 - Mean Temperature of Warmest Quarter, BIO11 - Mean Temperature of Coldest Quarter, BIO16 - Precipitation of Wettest Quarter, BIO17 - Precipitation of Driest Quarter, BIO18 - Precipitation of Warmest Quarter, BIO19 - Precipitation of Coldest Quarter);

- monthly means (BIO5 - Maximum Temperature of Warmest Month, BIO6 - Minimum Temperature of Coldest Month, BIO13 - Precipitation of Wettest Month, BIO14 - Precipitation of Driest Month).

These type of variables approximate either the total energy inputs for the ecosystem for the given period (temperature variables), or total water available for particular species (in many cases a serious limiting factor). For xeric species, adapted to warm conditions and less water, parameters such as BIO17 (Precipitations Of Driest Quarter), or BIO9 (Mean Temperature Of Driest Quarter) should be the most important. For species which love warmth and humidity, BIO10 (Mean Temperatures Of Warmest Quarter) or BIO18 (Precipitations Of Warmest Quarter) are expected to be the most relevant. For arctic and alpine species, BIO11 (Mean Temperature Of Coldest Quarter) and BIO19 (Precipitations Of Coldest Quarter) are typically the most important.

Aside from these variables, which are direct (they represent either temperature averages or precipitation totals for various periods of time), there are several variables which deal with the variability of temperatures and precipitations. The definition and formula of each of the derived variables [6] is:

BIO2 - Mean diurnal range is defined as "the mean of the monthly temperature ranges (monthly maximum minus monthly minimum)". BIO2 $=\sum\left(\operatorname{Tmax}_{\mathrm{i}}-\operatorname{Tm}_{\mathrm{in}}\right) / 12$, where $i$ has values between 1 and 12 .

BIO3 - Isothermality is a complex parameter, quantifying how large the day-to-night temperatures oscillate relative to summer-to-winter oscillations. It calculated as $(\mathrm{BIO} 2 / \mathrm{BIO} 7 \mathrm{x}$ 100).

BIO4 - Temperature Seasonality is defined as "the amount of temperature variation over a given year (or averaged years) based on the standard deviation (variation) of monthly mean averages". The calculation formula is BIO4 = SD $\{$ Tavg1, Tavg2 .... Tavg12\}. Multiplication of the result by 100 is done to retain significant digits.

BIO7 - Temperature Annual Range (BIO5-BIO6) is defined as "the variation of temperature over a year". It is calculated as $\mathrm{BIO}=\mathrm{BIO5-BIO6}$

BIO15 - Precipitation Seasonality (Coefficient of Variation) is a measure of variation in monthly precipitation totals over the course of the year. The calculation formula is $B I O 15=[S D$ $\{P P T 1, \ldots . . P P T 12\}] /[1+(B I O 12 / 12)] \times 100-$ i.e. the report between the standard deviation of monthly total precipitations and the mean precipitation (calculated from the yearly total precipitation). A small value (1) is added to the denominator, in order to avoid the extreme cases where BIO12/12 has values below 1. In essence, it calculates how much is the monthly variation of precipitation in relation to the average monthly value (in percent).

These indirect parameters help provide information on the relevance of temperature and precipitation fluctuations for different species. BIO3 - Isothermality is known to be useful for tropical, insular and maritime environments [6].

The data analysis has been executed in $\mathrm{R}$ software [10], using the packages raster [3], rgdal [1], openxlsx [13]. For each of the 11 temperature variables and 8 precipitation variables, 
several summaries have been created. First, for each variable current values (averages for the period 1950-2000) were extracted from the predicted values of each GCM-RCP-year combination, thus generating maps with the forecasted difference. In a second step, the average value at country level of each GCM-RCP-year combination was calculated. The resulting average values ( 88 per variable, 11 GCMs x 2 years $\times 4$ RCPs) were then grouped in a table, with combinations of year and RCP as rows, and GCMs as columns. The highest and lowest predicted average change of each row was highlighted, underlining which GCM has the most extreme prediction for Romanian territory in each combination of year and RCP. Additionally, the tables include the standard deviation for each combination of GCM, RCP and year. This value offers information about the spatial variation of the predicted difference from current values, as approx. $96 \%$ of all values fall within \pm 2 standard deviations from the mean.

In order to assess better the spatial variation of change, maps with the averages of the 11 GCMs for the 2 extreme RCP scenarios (26 and 85) were generated for each variable (year 2050), as well as maps with their standard deviations (as a measure of agreement between GCMs). The maps were generated in R software [10], using the raster and rgdal packages [1, 3]. For consistency, all the map colour palettes range from blue colour (low values) to red colour (high values).

\section{Results}

As the results are individualized for each variable, they are assessed sequentially.

\section{BIO1 - Annual Mean Temperature}

For the Annual mean temperature (BIO1 variable), the most extreme GCM is $h d$, which predicts up to $+6.3^{\circ} \mathrm{C}$ on average, in the worst case scenario (RCP85) for 2070. This is an extreme prediction however, as most country average predictions of this $\mathrm{GCM}$ for the years 2050-2070 are between $+2.5^{\circ} \mathrm{C}$ and $+4^{\circ} \mathrm{C}$ (Tab.3). The smallest increase is predicted by the $m g$ GCM, which indicates a worst scenario of $+3^{\circ} \mathrm{C}$ on average (year 2070, RCP85), and has all other predictions between $+0.9-1.8^{\circ} \mathrm{C}$.

A more moderate scenario appears to be $b c$, with a minimum temperature increase of $+1.7^{\mathrm{O}} \mathrm{C}$ and a maximum of $+4.2^{\mathrm{O}} \mathrm{C}$ (both values are country averages). This model also has very little spatial variation for predicted differences (with standard deviations of maximum $0.13^{\mathrm{O}} \mathrm{C}$ ).

In regards to the spatial variability of change, annual mean temperature increase appears to be higher in the eastern and southern part of Romania and the western plain, but that depends on RCP scenario (Fig. 1). The variability between regions in regard to the average predicted difference appears to be small (less than $1^{\circ} \mathrm{C}$, Fig. 1). This is also valid for all 88 GCM-RCPyear combinations considered (maximum SD $0.37^{\mathrm{O}} \mathrm{C}$, Tab. 3 ).

The agreement between models varies depending on RCP scenario. For both scenarios presented (RCP26 and RCP85), there is higher consensus for the north of Romania (see standard deviation maps, lower left corner of each map). In the RCP26 scenario, the regions with the highest mean predicted increase are also those with less agreement between models (higher standard deviations). For the RCP85 scenario, the agreement of GCMs in these regions is higher, and there is less consensus with regard to the extreme west of Romania. 
Table 3: Country average (and standard deviation) of predicted differences for each GCM-RCP-year combination (units: ${ }^{\circ} \mathbf{C} \times 10$ ); minimum and maximum values for each row are highlighted.

\begin{tabular}{|c|c|c|c|c|c|c|c|c|c|c|c|c|}
\hline Jear & RCP & bc & cc & gs & hd & he & ip & me & mg & mi & $\mathbf{m r}$ & no \\
\hline 2050 & RCP26 & 17.52 & 16.69 & 14.58 & 36.14 & 30.73 & 29.50 & 33.12 & 9.59 & 36.27 & 31.87 & 18.98 \\
\hline \multirow{15}{*}{2070} & SD & 0.50 & 0.53 & 0.50 & 1.77 & 1.07 & 1.45 & 1.07 & 0.64 & 2.73 & 2.22 & 0.63 \\
\hline & RCP45 & 23.33 & 20.46 & 21.37 & 37.25 & 34.68 & 33.21 & 35.05 & 12.09 & 33.65 & 33.03 & 26.26 \\
\hline & SD & 0.71 & 0.55 & 0.74 & 2.07 & 1.22 & 1.57 & 1.18 & 0.78 & 1.87 & 1.85 & 0.73 \\
\hline & RCP60 & 26.24 & 19.28 & 22.14 & 36.31 & 33.66 & 31.20 & 32.03 & 13.51 & 32.55 & 31.42 & 21.49 \\
\hline & SD & 1.24 & 0.76 & 0.65 & 2.21 & 1.61 & 1.62 & 0.80 & 0.61 & 1.61 & 1.67 & 0.56 \\
\hline & RCP85 & 31.30 & 27.49 & 26.20 & 47.30 & 42.47 & 40.47 & 42.18 & 18.71 & 43.43 & 41.35 & 27.07 \\
\hline & SD & 1.01 & 0.74 & 0.78 & 3.55 & 1.79 & 1.72 & 1.28 & 0.91 & 2.38 & 2.30 & 0.64 \\
\hline & RCP26 & 18.57 & 17.87 & 14.45 & 29.88 & 31.78 & 28.88 & 34.97 & 13.27 & 35.57 & 29.82 & 23.34 \\
\hline & SD & 0.63 & 1.35 & 0.65 & 1.76 & 1.11 & 1.55 & 1.11 & 0.91 & 2.77 & 1.66 & 1.55 \\
\hline & RCP45 & 27.12 & 24.40 & 24.99 & 47.74 & 41.36 & 38.34 & 42.25 & 15.98 & 40.23 & 40.35 & 29.52 \\
\hline & SD & 0.62 & 0.85 & 0.85 & & 1.49 & 1.96 & 1.29 & 0. & 2.91 & 2.18 & 0.76 \\
\hline & RCP60 & 31.55 & 25.47 & 24.91 & 40.77 & 46.15 & 38.90 & 41.54 & 16.93 & 43.35 & 39.44 & 29.35 \\
\hline & SD & 1.31 & 0.71 & 0.68 & 1.91 & 1.82 & 1.82 & 1.30 & 0.88 & 2.29 & 1.91 & 0.94 \\
\hline & RCP85 & 42.57 & 38.52 & 34.92 & 63.16 & 60.84 & 58.17 & 54.12 & $\mathbf{3 0 . 3 3}$ & 55.17 & 55.29 & 41.53 \\
\hline & SD & 1.28 & 0.97 & 0.76 & 3.70 & 3.02 & 2.16 & 1.44 & 1.09 & 2.62 & 2.37 & 0.88 \\
\hline
\end{tabular}
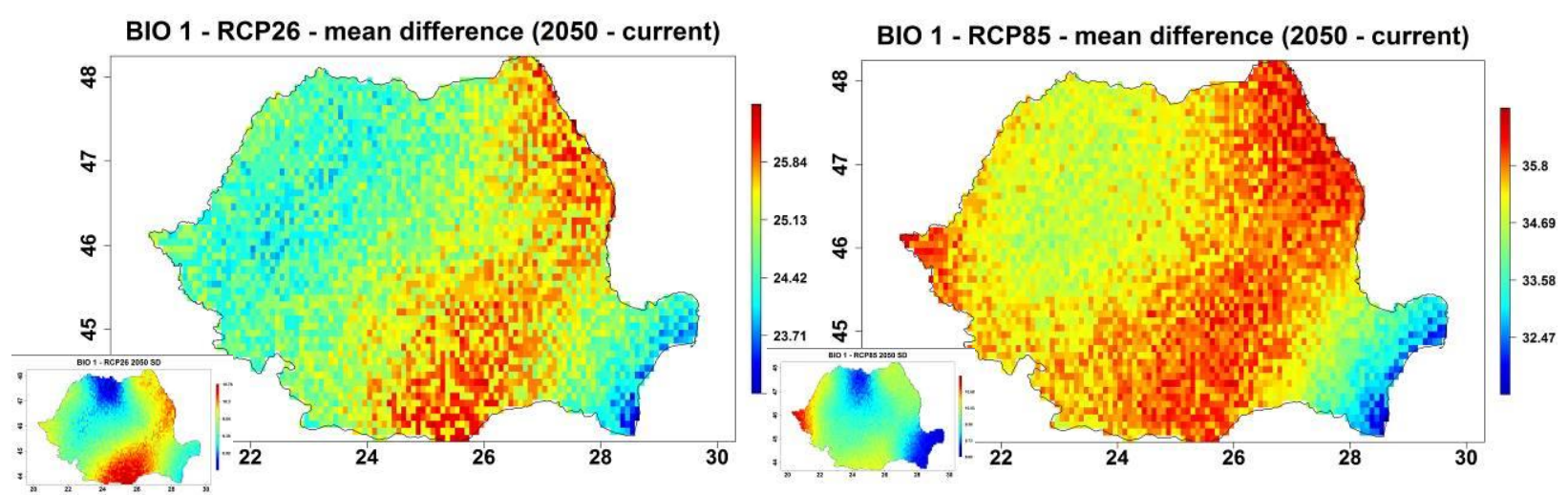

Fig. 1: Average GCM difference between predicted and current values of the annual mean temperature (BIO1) in 2050 - RCP26 (left), RCP85 (right). Standard deviations are presented in the lower left corner for both cases (SD values between $0.9-1{ }^{\mathrm{O}} \mathrm{C}$ for RCP26, SD between $0.8-1.1^{\mathrm{O}} \mathrm{C}$ for RCP85).

\section{BIO2 - Mean Diurnal Range (Mean of monthly (max temp - min temp))}

Current values of this variable vary between 56 and 110 for Romanian territory at this resolution. A total of 18 combinations of GCM-RCP-year (from the total of 88 possible) indicate a country average decrease of mean diurnal range (Tab.4). These are all the ip and $m g$ GCMs predictions, as well as $2 \mathrm{gs}$ predictions. The 2 models with negative predictions also have larger standard deviations, implying a larger spatial variability of change.

The rest of $8 \mathrm{GCMs}$ indicate an increase in mean diurnal range (amplitude from cca. +0.1 to $+1.5^{\circ} \mathrm{C}$ country average). The most significant increase is predicted by the $m c$ GCM, but also the $h d$ GCM has an important increase predicted, especially for the RCP85 scenario.

Spatial variability between regions is rather low (below $0.7^{\circ} \mathrm{C}$ difference between predicted average values, Fig. 2), and the agreement between models is lowest in the south-west part for RCP26, namely in the south for RCP85 (lower left maps, Fig. 2). 
Table 4: Country average (and standard deviation) of predicted differences for each GCM-RCP-year combination (units: ${ }^{\circ} \mathbf{C} \mathbf{x} 10$ ); minimum and maximum values for each row are highlighted.

\begin{tabular}{|c|c|c|c|c|c|c|c|c|c|c|c|c|}
\hline Year & RCP & bc & cc & gs & hd & he & ip & mc & mg & mi & $\mathbf{m r}$ & no \\
\hline \multirow[t]{8}{*}{2050} & RCP26 & 1.87 & 3.65 & -0.13 & 9.51 & 6.10 & -3.27 & 10.97 & -3.29 & 8.10 & 7.44 & 4.05 \\
\hline & SD & 0.63 & 1.33 & 0.56 & 1.72 & 1.58 & 3.82 & 1.52 & 3.59 & 3.43 & 2.45 & 1.15 \\
\hline & RCP45 & 5.26 & 5.44 & 0.35 & 7.92 & 6.32 & -6.65 & 11.22 & -3.96 & 5.57 & 5.41 & 8.64 \\
\hline & SD & 0.84 & 1.42 & 0.94 & 1.60 & 1.63 & 3.20 & 1.76 & 3.91 & 3.00 & 2.74 & 2.24 \\
\hline & RCP60 & 4.22 & 6.40 & 0.77 & 8.81 & 6.98 & -6.66 & 9.79 & -2.55 & 4.68 & 5.41 & 6.66 \\
\hline & SD & 1.66 & 0.81 & 1.73 & 1.95 & 2.60 & 1.43 & 3.48 & 1.75 & 2.20 & 1.71 & 1.66 \\
\hline & RCP85 & 4.84 & 6.89 & -0.52 & 14.88 & 7.31 & -4.26 & 11.99 & -2.71 & 8.79 & 6.02 & 7.64 \\
\hline & SD & 0.82 & 1.65 & 0.68 & 2.49 & 1.96 & 4.12 & 1.79 & 3.73 & 3.67 & 2.86 & 1.98 \\
\hline \multirow[t]{8}{*}{2070} & RCP26 & 2.45 & 0.30 & 0.73 & 9.10 & 6.34 & -6.76 & 12.11 & -2.64 & 8.80 & 4.62 & 1.99 \\
\hline & SD & 0.80 & 3.49 & 0.55 & 1.63 & 1.74 & 3.31 & 1.76 & 3.85 & 3.59 & 1.29 & 2.55 \\
\hline & $\mathrm{RCP} 45$ & 3.38 & 6.88 & 0.91 & 12.37 & 7.04 & -6.58 & 12.76 & -3.71 & 9.00 & 6.75 & 8.86 \\
\hline & SD & 0.69 & 1.75 & 1.07 & 2.37 & 1.91 & 3.58 & 2.01 & 3.95 & 4.22 & 2.99 & 2.44 \\
\hline & RCP60 & 4.71 & 8.34 & 0.60 & 10.06 & 8.06 & -8.22 & 12.60 & -4.30 & 7.73 & 5.65 & 9.77 \\
\hline & SD & 0.88 & 1.95 & 0.77 & 1.72 & 2.32 & 3.52 & 2.20 & 3.78 & 2.03 & 1.86 & 2.17 \\
\hline & RCP85 & 6.35 & 8.62 & 0.65 & 15.83 & 10.31 & -3.17 & 13.98 & -3.39 & 6.52 & 8.32 & 9.60 \\
\hline & SD & 1.11 & 2.10 & 0.94 & 2.60 & 2.69 & 5.10 & 2.22 & 3.77 & 3.61 & 3.28 & 2.33 \\
\hline
\end{tabular}
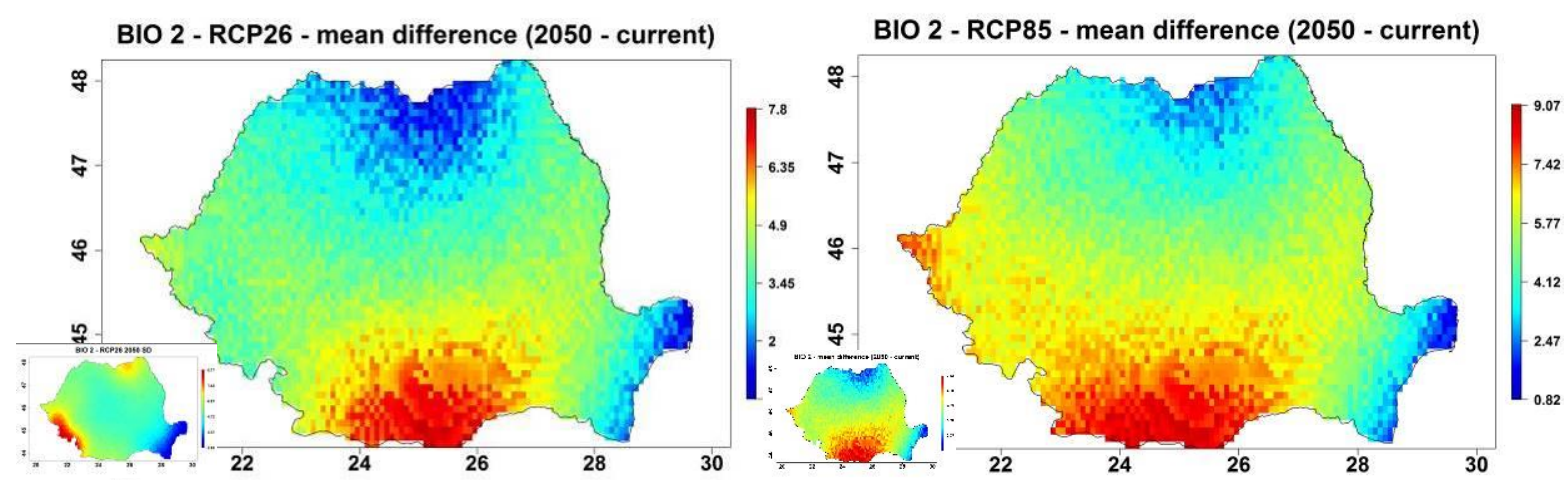

Fig. 2: Average GCM difference between predicted and current values of mean diurnal range (BIO2) in 2050

- RCP26 (left), RCP85 (right). Standard deviations are presented in the lower left corner for both cases (SD values between $2-8.7^{\circ} \mathrm{C}$ x 10 for RCP26, SD between $3.6-9.8^{\mathrm{O}} \mathrm{C}$ x 10 for RCP85).

\section{BIO3 - Isothermality (BIO2/BIO7) (* 100)}

Current values of this variable range between 20 and 33 in Romania. As this variable is obtained by multiplying a report (BIO2/BIO7) by 100, it implies that the values of the fraction are smaller than 1 (BIO7 is 3 to 5 times higher than $\mathrm{BIO} 2$, in other words temperature annual range-BIO7 is 3 to 5 times higher than mean diurnal range-BIO2).

In this context, the average change is not very high (values between approx. -2 and +2 , with small standard deviations, tab. 5). The spatial pattern of variation is not very clear. It indicates an influence of distance from large water masses (Black Sea, Mediterranean Sea) on this parameter, and this factor is independent of climate change. The high standard deviation compared to the mean is an expression of high model disagreement. Highest increase is predicted by the $m c$ GCM, based on its predicted increase of BIO2 ( $m c$ is the GCM predicting the highest increase in mean diurnal range). 
Table 5: Country average (and standard deviation) of predicted differences for each GCM-RCP-year combination (units: percent); minimum and maximum values for each row are highlighted.

\begin{tabular}{|c|c|c|c|c|c|c|c|c|c|c|c|c|}
\hline Year & RCP & bc & cc & gs & hd & he & ip & mc & mg & mi & $\mathbf{m r}$ & no \\
\hline \multirow[t]{8}{*}{2050} & $\mathrm{RCP} 26$ & 0.00 & -0.45 & 0.33 & 0.93 & -0.03 & 0.36 & 1.45 & -0.75 & 0.22 & -0.58 & -0.46 \\
\hline & SD & 0.46 & 0.55 & 0.49 & 0.99 & 0.83 & 0.61 & 0.56 & 1.18 & 0.68 & 0.70 & 0.52 \\
\hline & RCP45 & -0.77 & -0.16 & 0.32 & -0.95 & -0.39 & 0.56 & 1.37 & -1.51 & -0.69 & -1.80 & 1.46 \\
\hline & SD & 0.53 & 0.51 & 0.47 & 0.97 & 1.08 & 0.57 & 0.57 & 1.21 & 0.73 & 0.67 & 0.86 \\
\hline & RCP60 & 0.69 & -0.11 & 1.10 & 0.23 & 0.01 & 0.11 & 0.64 & 1.26 & 0.32 & -0.40 & 1.51 \\
\hline & SD & 0.50 & 0.57 & 0.41 & 1.04 & 0.81 & 0.68 & 0.51 & 1.27 & 0.65 & 0.84 & 0.57 \\
\hline & RCP85 & -2.12 & -0.63 & 0.77 & 0.46 & -0.46 & 0.86 & 2.01 & 0.66 & -1.14 & -1.55 & 0.17 \\
\hline & SD & 0.54 & 0.60 & 0.47 & 1.04 & 1.20 & 0.75 & 0.64 & 1.21 & 0.75 & 0.79 & 0.62 \\
\hline \multirow[t]{8}{*}{2070} & RCP26 & -0.05 & -1.41 & 0.31 & 1.75 & 0.58 & -0.09 & 1.68 & -0.15 & 0.28 & -1.21 & 0.34 \\
\hline & SD & 0.52 & 1.16 & 0.48 & 0.94 & 0.89 & 0.67 & 0.60 & 1.16 & 0.62 & 0.60 & 0.83 \\
\hline & RCP45 & 0.47 & 0.17 & 0.50 & -0.12 & 0.25 & 1.11 & 2.07 & 0.25 & -1.05 & -1.95 & -0.12 \\
\hline & SD & 0.61 & 0.66 & 0.50 & 1.10 & 0.90 & 0.55 & 0.63 & 1.35 & 0.58 & 0.65 & 0.72 \\
\hline & RCP60 & -1.09 & 0.70 & 0.63 & -0.38 & 0.41 & -0.41 & 1.60 & -0.34 & -0.64 & -1.02 & 1.47 \\
\hline & SD & 0.48 & 0.61 & 0.49 & 1.11 & 1.16 & 0.54 & 0.61 & 1.15 & 0.73 & 0.83 & 0.65 \\
\hline & RCP85 & 0.03 & -0.81 & 1.44 & -0.59 & -0.69 & 0.65 & 1.45 & 1.04 & -2.42 & -1.52 & 0.55 \\
\hline & $\mathrm{SD}$ & 0.53 & 0.69 & 0.54 & 1.39 & 1.22 & 0.60 & 0.61 & 1.24 & 0.83 & 0.87 & 0.69 \\
\hline
\end{tabular}
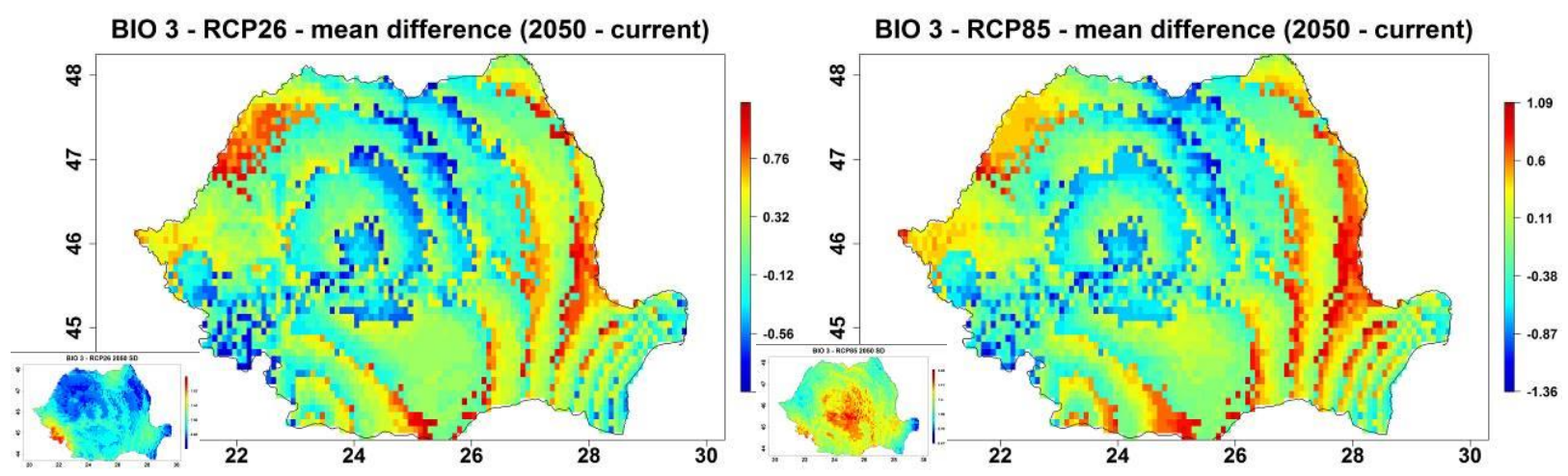

Fig. 3: Average GCM difference between predicted and current values of isothermality (BIO3) in 2050 RCP26 (left), RCP85 (right). Standard deviations are presented in the lower left corner for both cases ( $\mathrm{SD}$ values between $0.61-2.16^{\circ} \mathrm{C}$ x 10 for RCP26, SD between $0.47-1.97^{\circ} \mathrm{C}$ x 10 for RCP85).

\section{BIO4 - Temperature Seasonality (standard deviation *100)}

Current values for BIO4 in Romania range between 6164 (at high altitudes) and 8654 (at low altitudes). The larger this value is, the greater the variability of temperature is over the year.

Not all GCM-RCP scenarios predict an increase of this variable in Romania. Twentythree of the 88 averages are negative (especially ip, $m g$ and $g_{s}$ GCMs). Of the remaining GCMs, $m r$ appears to indicate the highest increase for this variable (Tab. 6).

Spatial variation is reduced (i.e. range of average values between $0.04-0.31^{\circ} \mathrm{C}$ for the $26 \mathrm{RCP}$ scenario, Fig. 4 large maps). Both RCP scenarios displayed show a more pronounced increase of temperature seasonality in the south of Romania. Model agreement is very low, as standard deviations have high values compared to the mean (Fig. 4, small maps). 
Table 6: Country average (and standard deviation) of predicted differences for each GCM-RCP-year combination (units: ${ }^{\circ} \mathbf{C} \times$ 1000); minimum and maximum values for each row are highlighted.

\begin{tabular}{|c|c|c|c|c|c|c|c|c|c|c|c|c|}
\hline Year & RCP & bc & cc & gs & hd & he & ip & mc & mg & mi & $\mathbf{m r}$ & no \\
\hline \multirow[t]{8}{*}{2050} & $\mathrm{RCP} 26$ & 461 & 419 & -38 & -55 & 227 & -385 & 246 & 112 & 209 & 767 & 391 \\
\hline & SD & 75 & 54 & 44 & 265 & 145 & 242 & 73 & 98 & 270 & 287 & 69 \\
\hline & $\mathrm{RCP} 45$ & 493 & 429 & -24 & 505 & 351 & -375 & 353 & 122 & 512 & 735 & 41 \\
\hline & SD & 99 & 54 & 59 & 252 & 242 & 232 & 91 & 74 & 205 & 194 & 135 \\
\hline & RCP60 & 209 & 470 & -103 & 35 & 288 & -447 & 385 & -350 & 152 & 435 & 106 \\
\hline & SD & 69 & 36 & 83 & 249 & 172 & 207 & 62 & 124 & 140 & 129 & 39 \\
\hline & RCP85 & 745 & 688 & -155 & 650 & 543 & -498 & 274 & -2 & 633 & 1002 & 587 \\
\hline & SD & 75 & 92 & 63 & 356 & 294 & 270 & 121 & 107 & 274 & 295 & 72 \\
\hline \multirow[t]{8}{*}{2070} & RCP26 & 154 & 535 & -26 & 123 & 85 & -474 & 171 & -235 & 334 & 585 & 377 \\
\hline & SD & 69 & 100 & 38 & 202 & 175 & 211 & 126 & 96 & 198 & 200 & 90 \\
\hline & RCP45 & 219 & 458 & -13 & 577 & 323 & -472 & 85 & -148 & 812 & 867 & 531 \\
\hline & SD & 139 & 79 & 81 & 305 & 206 & 268 & 119 & 98 & 302 & 272 & 111 \\
\hline & RCP60 & 427 & 429 & -39 & 484 & 328 & -553 & 252 & -126 & 663 & 648 & 351 \\
\hline & SD & 115 & 54 & 76 & 300 & 287 & 268 & 184 & 114 & 220 & 217 & 78 \\
\hline & RCP85 & 606 & 900 & -109 & 831 & 900 & -422 & 281 & -471 & 1054 & 1196 & 526 \\
\hline & SD & 160 & 105 & 110 & 440 & 388 & 372 & 157 & 129 & 231 & 341 & 80 \\
\hline
\end{tabular}

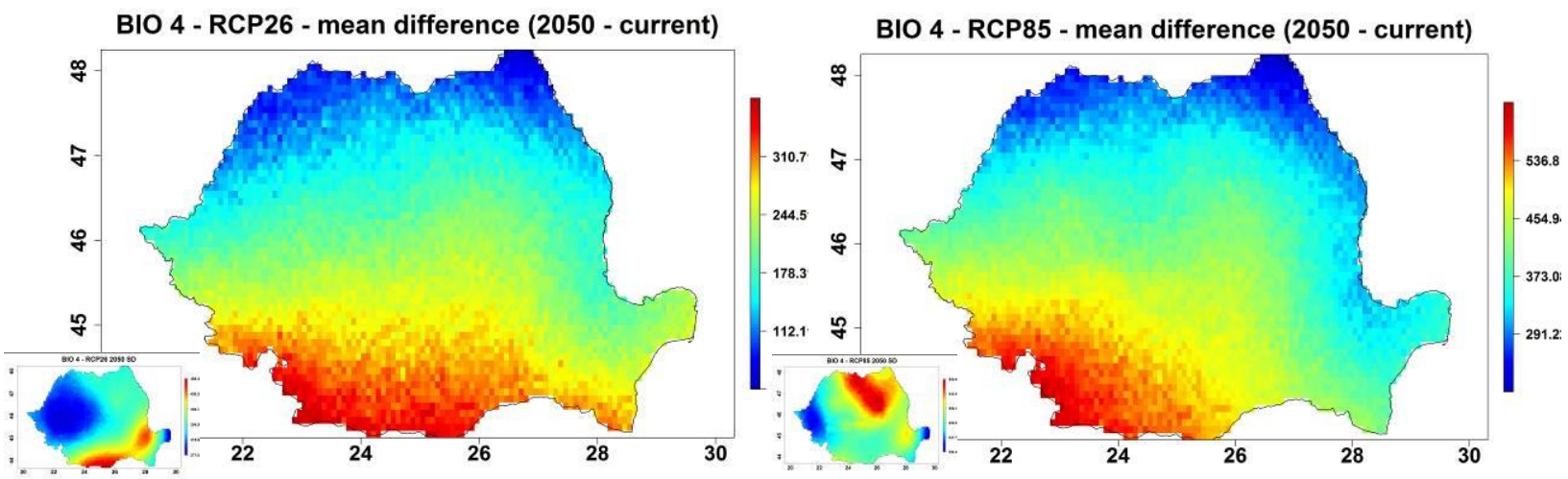

Fig. 4: Average GCM difference between predicted and current values of the temperature seasonality (BIO4) in 2050 - RCP26 (left), RCP85 (right). Standard deviations are presented in the lower left corner for both cases (SD values between $277-468^{\circ} \mathrm{C}$ x 1000 for RCP26, SD between $394-580^{\circ} \mathrm{C}$ x 1000 for RCP85).

\section{BIO5 - Max. Temperature of Warmest Month}

In Romania the warmest month is in general July, with the exception of mountain regions, where, at high altitudes, the warmest month is August (based on averages between 1960 and 2000).

The increase of the maximum temperature of the warmest month is highly variable between scenarios and models, country averages ranging between $+0.83^{\circ} \mathrm{C}(m g \mathrm{GCM}, 26 \mathrm{RCP}$, 2050) to $+12.19^{\mathrm{O}} \mathrm{C}$ ( $h d \mathrm{GCM}, 85 \mathrm{RCP}, 2070$ ) (Tab. 7). The GCM indicating the highest country average increase is in general $h d\left(+4.8^{\mathrm{O}} \mathrm{C}\right.$ to $\left.+12.1^{\mathrm{O}} \mathrm{C}\right)$, while the lowest increase is predicted by $m g\left(+0.8^{\circ} \mathrm{C}\right.$ to $\left.+2.6^{\circ} \mathrm{C}\right)$. Spatial variation (expressed by standard deviation, Tab. 7$)$ is higher for models indicating higher temperature increase.

In regards to the spatial variation of average values, the highest increase is predicted for the south, south-west and central parts of Romania (Fig. 5, large maps), but these are also 
regions with lowest agreement between models (Fig. 5, small maps).

Table 7: Country average (and standard deviation) of predicted differences for each GCM-RCP-year combination (units: ${ }^{\circ} \mathbf{C} \times 10$ ); minimum and maximum values for each row are highlighted.

\begin{tabular}{|c|c|c|c|c|c|c|c|c|c|c|c|c|}
\hline Year & RCP & bc & cc & gs & hd & he & ip & mc & mg & mi & $\mathbf{m r}$ & no \\
\hline \multirow[t]{8}{*}{2050} & $\mathrm{RCP} 26$ & 28.5 & 29.6 & 14.4 & 61.9 & 49.2 & 33.6 & 44.7 & 8.3 & 51.9 & 59.6 & 36.0 \\
\hline & SD & 2.3 & 2.1 & 0.7 & 7.0 & 6.3 & 1.7 & 1.4 & 1.7 & 10.1 & 11.3 & 2.9 \\
\hline & $\mathrm{RCP} 45$ & 41.4 & 35.1 & 23.7 & 71.7 & 63.5 & 32.3 & 45.8 & 14.6 & 47.9 & 61.5 & 41.3 \\
\hline & SD & 3.7 & 1.8 & 1.3 & 8.3 & 8.6 & 1.7 & 2.3 & 1.6 & 6.8 & 7.9 & 2.7 \\
\hline & RCP60 & 37.5 & 33.6 & 23.3 & 67.4 & 55.1 & 29.2 & 40.1 & 9.6 & 40.1 & 50.3 & 33.0 \\
\hline & SD & 2.2 & 2.2 & 1.1 & 8.7 & 6.4 & 1.4 & 2.1 & 2.1 & 5.0 & 5.2 & 2.3 \\
\hline & RCP85 & 55.2 & 49.1 & 25.1 & 94.5 & 72.1 & 41.3 & 53.3 & 18.4 & 73.7 & 74.5 & 49.8 \\
\hline & SD & 4.0 & 3.6 & 1.2 & 12.5 & 10.4 & 1.3 & 2.7 & 2.2 & 12.2 & 10.2 & 4.0 \\
\hline \multirow[t]{8}{*}{2070} & RCP26 & 29.6 & 28.6 & 15.2 & 48.5 & 48.9 & 30.2 & 45.5 & 12.1 & 52.1 & 54.5 & 33.8 \\
\hline & SD & 3.9 & 1.9 & 1.8 & 4.1 & 6.0 & 1.2 & 3.6 & 2.2 & 8.3 & 5.9 & 2.7 \\
\hline & RCP45 & 40.6 & 41.7 & 28.4 & 87.9 & 66.9 & 38.4 & 53.7 & 13.4 & 65.4 & 76.2 & 57.3 \\
\hline & SD & 3.0 & 1.9 & 1.8 & 11.0 & 7.4 & 2.1 & 2.7 & 1.9 & 12.2 & 9.7 & 4.5 \\
\hline & RCP60 & 52.4 & 43.5 & 26.5 & 75.2 & 73.5 & 41.9 & 51.0 & 19.3 & 63.9 & 67.9 & 50.2 \\
\hline & SD & 3.8 & 2.8 & 1.7 & 8.1 & 9.3 & 2.2 & 3.6 & 3.0 & 7.3 & 7.3 & 3.5 \\
\hline & RCP85 & 64.8 & 64.4 & 36.0 & 122.0 & 100.6 & 63.6 & 68.2 & 26.5 & 90.8 & 97.4 & 67.9 \\
\hline & $\mathrm{SD}$ & 4.8 & 3.2 & 2.3 & 16.6 & 13.5 & 4.0 & 2.7 & 2.6 & 8.5 & 11.1 & 4.1 \\
\hline
\end{tabular}

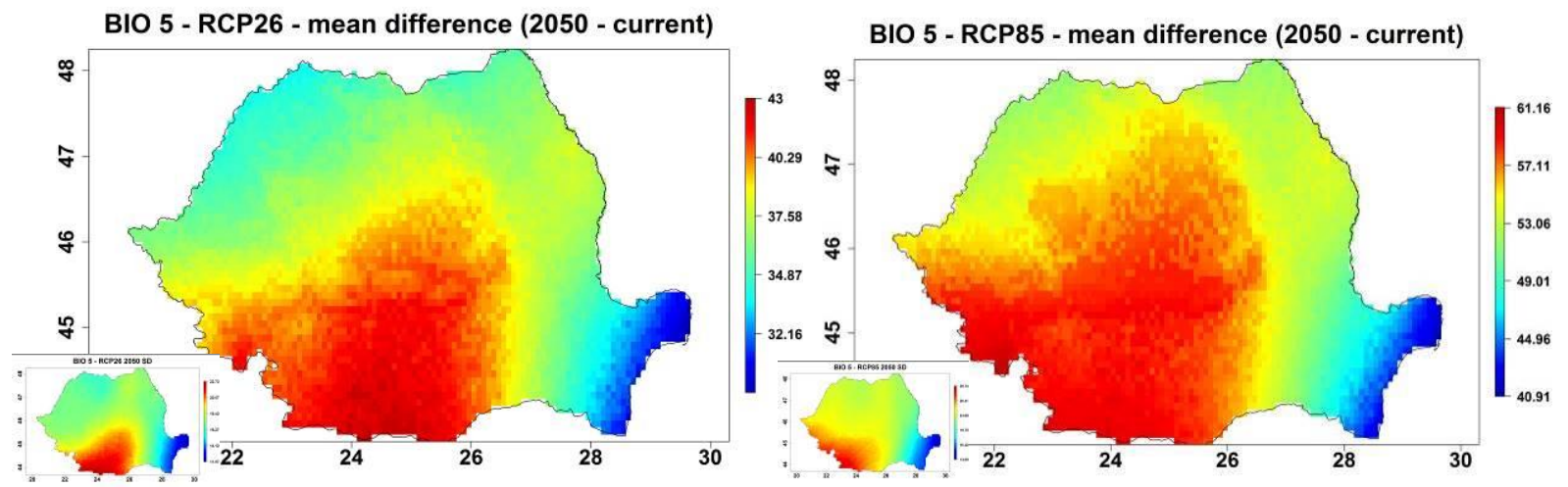

Fig. 5: Average GCM difference between predicted and current values for the max. temperature of the warmest month in 2050 - RCP26 (left), RCP85 (right). Standard deviations are presented in the lower left corner for both cases (SD values between $11.97-22.65^{\circ} \mathrm{C}$ x 10 for RCP26, SD between $13.09-29.71^{\circ} \mathrm{C} \mathrm{x}$ 10 for RCP85).

\section{BIO6 - Min. Temperature of Coldest Month}

Based on averages from 1960 to 2000, the coldest month is January throughout the entire country. The predicted country average increase for this variable ranges between $+1.16^{\mathrm{O}} \mathrm{C}(c c$ GCM, 60 RCP, 2050) and $+8.05^{\circ} \mathrm{C}$ (ip GCM, 85RCP, 2070) (Tab. 8). The ip GCM is constantly indicating the highest increase for this parameter, while $c c$ is indicating usually the lowest increase (maximum $+2.6^{\mathrm{O}} \mathrm{C}$ country average).

The spatial variability of averaged differences indicates a higher increase of cold month temperatures at higher latitudes, with the north of the country warming more than the south (Fig. 6, large maps). Model agreement is higher near the Black Sea, and lower towards the west and parts of the north (Fig. 6, small maps). 
Table 8: Country average (and standard deviation) of predicted differences for each GCM-RCP-year combination (units: ${ }^{\circ} \mathbf{C} \times$ 10); minimum and maximum values for each row are highlighted.

\begin{tabular}{|c|c|c|c|c|c|c|c|c|c|c|c|c|}
\hline Year & RCP & bc & cc & gs & hd & he & ip & mc & mg & mi & $\mathbf{m r}$ & no \\
\hline \multirow[t]{8}{*}{2050} & RCP26 & 22.4 & 13.0 & 18.1 & 41.5 & 29.3 & 47.9 & 24.8 & 11.6 & 27.7 & 28.7 & 17.7 \\
\hline & SD & 2.4 & 1.8 & 1.6 & 4.1 & 2.8 & 7.2 & 2.3 & 1.8 & 2.0 & 3.0 & 2.1 \\
\hline & RCP45 & 15.9 & 15.6 & 25.6 & 35.0 & 38.7 & 59.6 & 24.6 & 12.0 & 22.2 & 22.9 & 28.8 \\
\hline & SD & 1.3 & 1.7 & 2.0 & 4.5 & 3.7 & 7.4 & 2.3 & 2.7 & 2.8 & 2.8 & 4.2 \\
\hline & RCP60 & 31.0 & 11.6 & 31.9 & 41.2 & 32.9 & 52.2 & 15.3 & 30.4 & 28.2 & 28.1 & 27.4 \\
\hline & SD & 3.9 & 1.6 & 2.1 & 4.4 & 3.3 & 7.1 & 2.0 & 3.5 & 1.9 & 1.8 & 2.2 \\
\hline & RCP85 & 14.8 & 19.7 & 34.7 & 51.4 & 43.4 & 63.6 & 36.4 & 33.9 & 31.4 & 36.8 & 27.2 \\
\hline & SD & 1.4 & 2.4 & 2.6 & 5.4 & 3.4 & 7.9 & 3.9 & 3.8 & 1.5 & 2.5 & 3.9 \\
\hline \multirow[t]{8}{*}{2070} & RCP26 & 21.2 & 13.1 & 16.2 & 37.6 & 34.9 & 51.5 & 24.6 & 19.5 & 26.6 & 25.7 & 31.1 \\
\hline & SD & 2.1 & 2.0 & 1.2 & 4.8 & 2.6 & 6.2 & 2.7 & 3.4 & 1.7 & 2.4 & 4.6 \\
\hline & RCP45 & 34.8 & 21.1 & 30.6 & 46.5 & 47.0 & 70.3 & 35.0 & 28.3 & 23.9 & 31.1 & 27.1 \\
\hline & SD & 4.0 & 2.4 & 2.4 & 3.8 & 3.3 & 9.3 & 2.5 & 3.2 & 1.7 & 3.2 & 2.8 \\
\hline & RCP60 & 25.0 & 24.0 & 31.1 & 38.0 & 52.0 & 64.7 & 27.9 & 30.0 & 31.2 & 37.7 & 34.7 \\
\hline & SD & 2.3 & 2.9 & 2.1 & 4.4 & 4.0 & 8.6 & 4.3 & 4.2 & 3.3 & 2.0 & 4.8 \\
\hline & RCP85 & 44.5 & 26.9 & 48.2 & 63.1 & 59.2 & 80.5 & 39.2 & 48.1 & 41.1 & 51.9 & 43.2 \\
\hline & SD & 3.1 & 2.5 & 2.4 & 5.7 & 3.8 & 10.8 & 3.8 & 5.2 & 3.3 & 4.2 & 3.3 \\
\hline
\end{tabular}
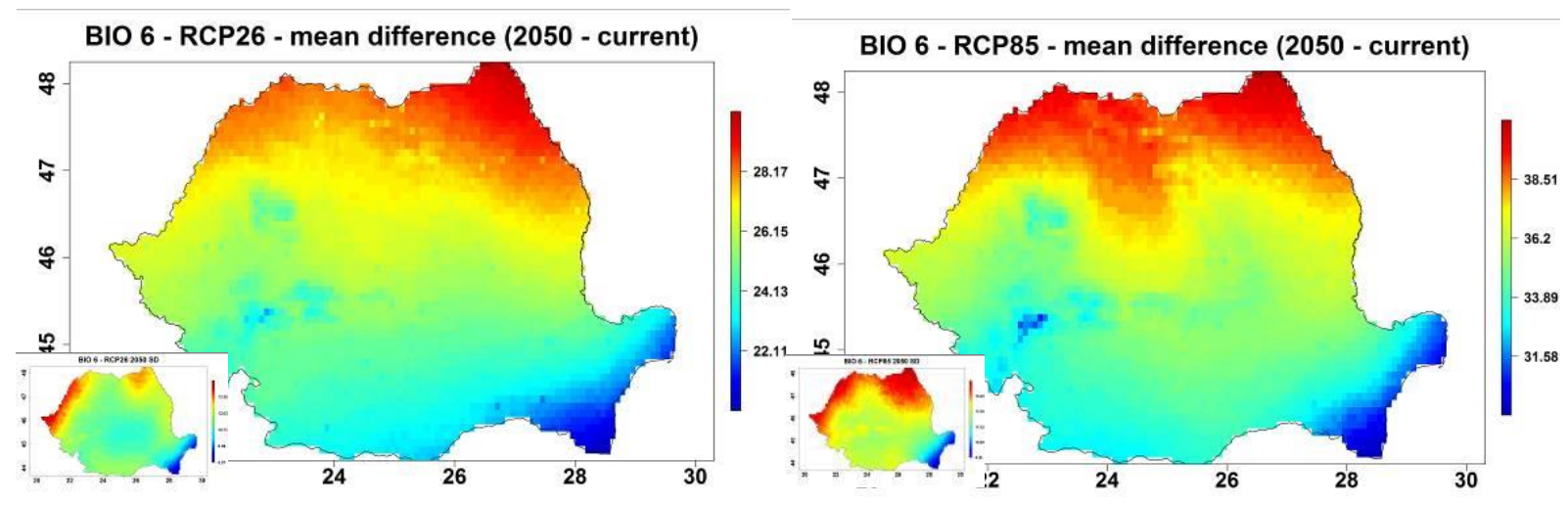

Fig. 6: Average GCM difference between predicted and current values for the min. temperature of the coldest month in 2050 - RCP26 (left), RCP85 (right). Standard deviations are presented in the lower left corner for both cases (SD values between $8.07-14.61^{\mathrm{O}} \mathrm{C}$ x 10 for RCP26, SD between $8.36-16.94^{\mathrm{O}} \mathrm{C} \times 10$ for RCP85).

\section{BIO7 - Temperature Annual Range (BIO5-BIO6)}

Current values of $\mathrm{BIO} 7$ range between 24.3 and $34.3^{\circ} \mathrm{C}$ at this resolution. For this variable, 23 of the 88 possible combinations of GCM, RCP and year indicate a country average decrease (ip GCM indicates the highest decrease, between $1.4^{\mathrm{O}} \mathrm{C}$ and $3.1^{\mathrm{O}} \mathrm{C}$, Tab. 9). Highest country average increase is predicted by the $m r\left(2.2^{\mathrm{O}} \mathrm{C}\right.$ to $4.5^{\circ} \mathrm{C}$ country average $)$ and $h d$ GCMs $\left(1^{\mathrm{O}} \mathrm{C}\right.$ to $5.8^{\mathrm{O}} \mathrm{C}$ country average). The predicted average increase appears to be higher at lower latitudes (the south of Romania, Fig. 7 large maps), but model agreement is rather low (Fig. 7, small maps). 
Table 9: Country average (and standard deviation) of predicted differences for each GCM-RCP-year combination (units: ${ }^{\circ} \mathbf{C} \times 10$ ); minimum and maximum values for each row are highlighted.

\begin{tabular}{|c|c|c|c|c|c|c|c|c|c|c|c|c|}
\hline Year & RCP & bc & cc & gs & hd & he & ip & mc & mg & mi & $\mathrm{mr}$ & no \\
\hline \multirow[t]{8}{*}{2050} & RCP26 & 6.1 & 16.6 & -3.7 & 20.4 & 19.9 & -14.4 & 19.9 & -3.3 & 24.2 & 30.9 & 18.2 \\
\hline & SD & 2.3 & 3.1 & 2.2 & 8.7 & 6.4 & 8.1 & 2.7 & 2.6 & 11.1 & 12.7 & 4.1 \\
\hline & RCP45 & 25.5 & 19.4 & -2.0 & 36.8 & 24.8 & -27.3 & 21.3 & 2.6 & 25.8 & 38.6 & 12.5 \\
\hline & SD & 4.2 & 2.2 & 2.9 & 7.8 & 10.0 & 8.3 & 3.7 & 3.1 & 9.2 & 9.6 & 4.9 \\
\hline & RCP60 & 6.4 & 22.0 & -8.7 & 26.2 & 22.2 & -23.0 & 24.8 & -20.8 & 11.9 & 22.2 & 5.6 \\
\hline & SD & 2.9 & 2.2 & 2.5 & 7.8 & 5.3 & 6.7 & 3.8 & 4.3 & 6.5 & 6.1 & 2.4 \\
\hline & RCP85 & 40.3 & 29.4 & -9.6 & 43.1 & 28.8 & -22.4 & 16.9 & -15.5 & 42.3 & 37.7 & 22.6 \\
\hline & SD & 3.4 & 4.0 & 3.2 & 11.1 & 11.5 & 8.8 & 5.2 & 4.8 & 13.0 & 11.4 & 5.8 \\
\hline \multirow[t]{8}{*}{2070} & RCP26 & 8.4 & 15.5 & -1.0 & 10.8 & 14.0 & -21.3 & 20.8 & -7.4 & 25.5 & 28.8 & 2.6 \\
\hline & SD & 4.8 & 2.1 & 1.8 & 6.0 & 6.9 & 6.9 & 5.5 & 4.5 & 9.1 & 6.5 & 4.6 \\
\hline & RCP45 & 5.8 & 20.6 & -2.1 & 41.4 & 19.9 & -31.9 & 18.7 & -14.9 & 41.5 & 45.1 & 30.2 \\
\hline & SD & 5.2 & 3.1 & 3.6 & 9.9 & 7.0 & 10.4 & 4.1 & 3.9 & 13.6 & 11.6 & 5.1 \\
\hline & RCP60 & 27.4 & 19.5 & -4.5 & 37.2 & 21.5 & -22.8 & 23.1 & -10.7 & 32.7 & 30.2 & 15.6 \\
\hline & SD & 3.0 & 2.9 & 3.2 & 9.5 & 10.2 & 9.6 & 7.1 & 5.6 & 9.1 & 7.8 & 5.5 \\
\hline & RCP85 & 20.3 & 37.4 & -12.2 & 58.8 & 41.4 & -16.9 & 28.9 & -21.6 & 49.8 & 45.5 & 24.8 \\
\hline & SD & 5.3 & 3.9 & 3.9 & 14.8 & 13.5 & 13.9 & 5.3 & 5.9 & 10.5 & 13.5 & 4.1 \\
\hline
\end{tabular}

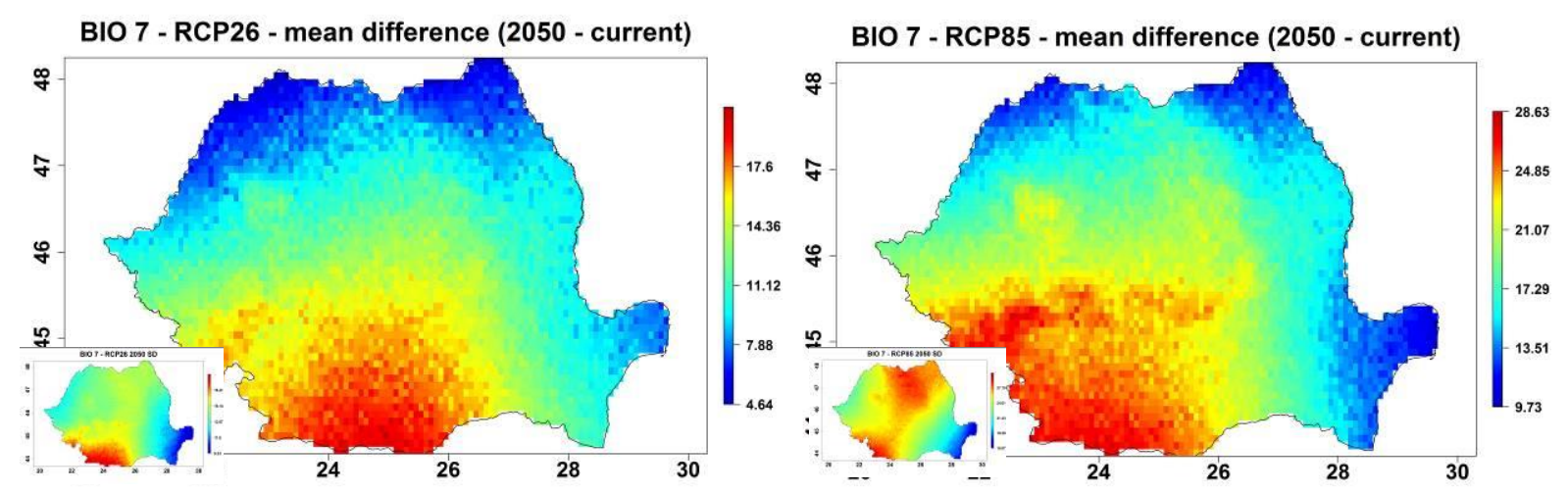

Fig. 7: Average GCM difference between predicted and current values of the temperature annual range in 2050 - RCP26 (left), RCP85 (right). Standard deviations are presented in the lower left corner for both cases (SD values between $9.33-20.61^{\circ} \mathrm{C} \times 10$ for RCP26, SD between $15.07-30.91^{\circ} \mathrm{C} \times 10$ for RCP85).

\section{BIO8 - Mean Temperature of Wettest Quarter}

The wettest quarter currently starts in May for almost the entire country (and includes the 3 months May, June, July) - based on averages between 1960 and 2000. There are very small areas near the Black Sea where the wettest quarter starts in July (months July, August, September) or October (months October, November, December). Current values lie in the range $7.8-20.8^{\mathrm{O}} \mathrm{C}$.

For this variable, there appears to be a great spatial variation of predicted values. While most of the country has a predicted increase in mean temperature of wettest quarter, there is high variability near the Black Sea (Fig. 8, large maps). The very abrupt gradient in predicted decrease of the mean temperature of the wettest quarter in 2050 near the seaside is based most likely on a change in wettest quarter for this region. 
Table 10: Country average (and standard deviation) of predicted differences for each GCM-RCP-year combination (units: ${ }^{\circ} \mathbf{C} \times 10$ ); minimum and maximum values for each row are highlighted.

\begin{tabular}{|c|c|c|c|c|c|c|c|c|c|c|c|c|}
\hline Year & RCP & bc & cc & gs & hd & he & ip & mc & mg & mi & mr & no \\
\hline \multirow[t]{8}{*}{2050} & RCP26 & 17.0 & 18.6 & 14.9 & -2.1 & 23.7 & 27.3 & 30.3 & 6.8 & 25.7 & 28.9 & 20.3 \\
\hline & SD & 20.1 & 10.4 & 6.6 & 21.4 & 15.3 & 13.3 & 18.5 & 18.6 & 19.3 & 15.9 & 14.1 \\
\hline & RCP45 & 16.5 & 24.0 & 22.7 & 10.0 & 2.9 & 42.8 & 35.1 & 0.6 & 34.0 & 34.5 & 25.8 \\
\hline & SD & 29.0 & 6.1 & 4.8 & 23.1 & 19.0 & 10.3 & 16.7 & 18.9 & 21.0 & 13.6 & 6.5 \\
\hline & RCP60 & 22.8 & 23.0 & 21.3 & -8.3 & 26.1 & 34.4 & 34.6 & 4.5 & 27.7 & 22.9 & 22.0 \\
\hline & SD & 8.4 & 5.9 & 6.6 & 5.1 & 18.1 & 11.1 & 6.7 & 13.9 & 28.6 & 18.3 & 6.6 \\
\hline & RCP85 & 18.3 & 17.5 & 28.1 & 3.9 & 8.1 & 46.5 & 41.7 & 15.6 & 38.6 & 32.9 & 27.0 \\
\hline & SD & 27.9 & 20.5 & 6.8 & 23.7 & 19.3 & 12.4 & 16.7 & 15.5 & 13.0 & 21.0 & 20.2 \\
\hline \multirow[t]{8}{*}{2070} & RCP26 & 10.0 & 22.6 & 14.9 & 5.3 & 24.1 & 20.6 & 35.7 & 10.5 & 25.8 & 18.6 & 27.8 \\
\hline & SD & 14.4 & 5.5 & 5.8 & 25.7 & 17.8 & 12.2 & 13.5 & 6.8 & 30.3 & 18.2 & 6.0 \\
\hline & RCP45 & 5.0 & 28.9 & 25.2 & 3.0 & 14.7 & 37.4 & 40.4 & 11.0 & 40.1 & 32.6 & 20.6 \\
\hline & SD & 19.8 & 13.2 & 10.7 & 19.1 & 23.0 & 10.7 & 9.2 & 12.6 & 16.2 & 19.7 & 22.4 \\
\hline & RCP60 & 5.5 & 25.7 & 31.5 & 1.1 & 15.1 & 32.0 & 41.5 & 14.2 & 43.3 & 26.4 & 23.8 \\
\hline & SD & 20.9 & 10.2 & 11.4 & 27.9 & 22.2 & 6.0 & 17.9 & 8.8 & 23.4 & 32.3 & 19.3 \\
\hline & RCP85 & 20.3 & 36.0 & 41.3 & 10.0 & 20.0 & 54.9 & 47.3 & 25.7 & 50.7 & 60.0 & 39.0 \\
\hline & SD & 32.6 & 30.1 & 19.8 & 35.7 & 15.6 & 11.4 & 18.1 & 6.3 & 38.1 & 16.8 & 12.5 \\
\hline
\end{tabular}
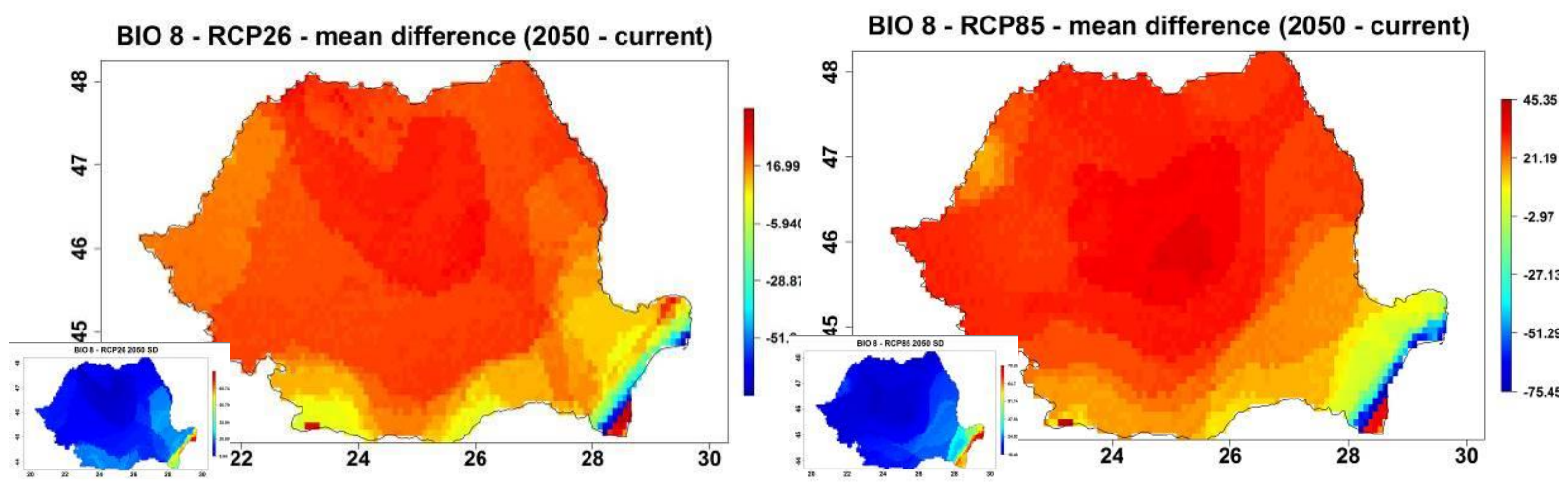

Fig. 8: Average GCM difference between predicted and current values of the mean temperature of the wettest quarter in 2050 - RCP26 (left), RCP85 (right). Standard deviations are presented in the lower left corner for both cases (SD values between $5.95-80.64^{\circ} \mathrm{C} \times 10$ for RCP26, SD between $10.46-$ $78.2^{\circ} \mathrm{C} \times 10$ for RCP85).

This situation makes it more difficult to assess correctly the average variation for the entire country (as expressed in Tab. 10). There are 2 combinations of GCM, RCP and year which have negative averages for the entire country, predicting a cooling in the wettest quarter (May, June, July). This change is most likely not caused by a cooling of temperatures in these months, but by a change in wettest quarter (from mostly summer months to probably spring or autumn). Given the high variability (i.e. high standard deviation values - Tab. 10, Fig. 8), it is recommended to be cautious in making assessments based on this variable for species distribution modeling.

\section{BIO9 - Mean Temperature of Driest Quarter}

Currently, the driest quarter starts in January for most of the country (based on averages between 1960 and 2000). For small parts of the country, the driest quarter starts in December, 
February, August or October (Fig. 9). Current values range between -6.2 and $17.8^{\mathrm{O}} \mathrm{C}$.

Table 11: Country average (and standard deviation) of predicted differences for each GCM-RCP-year combination (units: ${ }^{\circ} \mathbf{C} \times 10$ ); minimum and maximum values for each row are highlighted.

\begin{tabular}{|c|c|c|c|c|c|c|c|c|c|c|c|c|}
\hline Year & RCP & bc & cc & gs & hd & he & ip & mc & mg & mi & $\mathbf{m r}$ & no \\
\hline \multirow[t]{8}{*}{2050} & RCP26 & 31.5 & 15.8 & 12.7 & 134.0 & 70.2 & 37.4 & 26.7 & 49.5 & 88.2 & 55.1 & 21.6 \\
\hline & SD & 47.5 & 28.6 & 12.5 & 82.2 & 70.0 & 22.5 & 20.9 & 56.1 & 71.6 & 69.3 & 22.3 \\
\hline & $\mathrm{RCP} 45$ & 48.4 & 46.9 & 23.5 & 123.9 & 111.5 & 37.1 & 52.3 & 84.2 & 117.0 & 52.5 & 47.9 \\
\hline & SD & 63.6 & 54.4 & 13.9 & 83.8 & 90.8 & 23.4 & 41.6 & 55.3 & 52.3 & 59.4 & 45.7 \\
\hline & RCP60 & 31.3 & 19.1 & 28.0 & 123.6 & 72.6 & 38.4 & 50.7 & 28.5 & 78.6 & 39.7 & 30.4 \\
\hline & SD & 23.0 & 21.3 & 20.2 & 92.2 & 72.6 & 23.9 & 55.2 & 49.7 & 69.0 & 38.2 & 23.4 \\
\hline & RCP85 & 122.7 & 58.1 & 31.4 & 171.6 & 123.0 & 46.9 & 68.8 & 98.0 & 124.5 & 64.4 & 64.8 \\
\hline & SD & 75.9 & 72.8 & 13.9 & 92.6 & 98.0 & 23.6 & 63.1 & 49.9 & 71.2 & 70.7 & 64.7 \\
\hline \multirow[t]{8}{*}{2070} & RCP26 & 82.1 & 28.9 & 24.9 & 83.2 & 84.3 & 31.4 & 34.6 & 21.7 & 81.6 & 47.7 & 34.7 \\
\hline & SD & 69.5 & 46.9 & 27.8 & 72.2 & 73.9 & 23.4 & 12.7 & 29.0 & 71.9 & 63.9 & 44.2 \\
\hline & RCP45 & 36.5 & 61.9 & 29.0 & 170.3 & 117.7 & 47.1 & 72.7 & 20.8 & 71.4 & 41.8 & 53.7 \\
\hline & SD & 40.0 & 58.4 & 15.3 & 73.3 & 84.3 & 22.5 & 45.4 & 26.1 & 68.8 & 43.2 & 59.3 \\
\hline & RCP60 & 71.8 & 29.1 & 26.0 & 148.4 & 111.8 & 41.1 & 52.7 & 46.3 & 75.3 & 51.6 & 41.0 \\
\hline & SD & 77.5 & 28.7 & 20.5 & 90.3 & 90.3 & 24.5 & 43.1 & 62.3 & 69.6 & 54.6 & 32.4 \\
\hline & RCP85 & 153.8 & 81.1 & 49.8 & 240.1 & 222.7 & 70.5 & 66.2 & 100.6 & 95.6 & 68.4 & 45.9 \\
\hline & SD & 62.3 & 73.5 & 34.9 & 63.8 & 75.2 & 18.2 & 40.3 & 36.9 & 84.0 & 63.7 & 24.1 \\
\hline
\end{tabular}

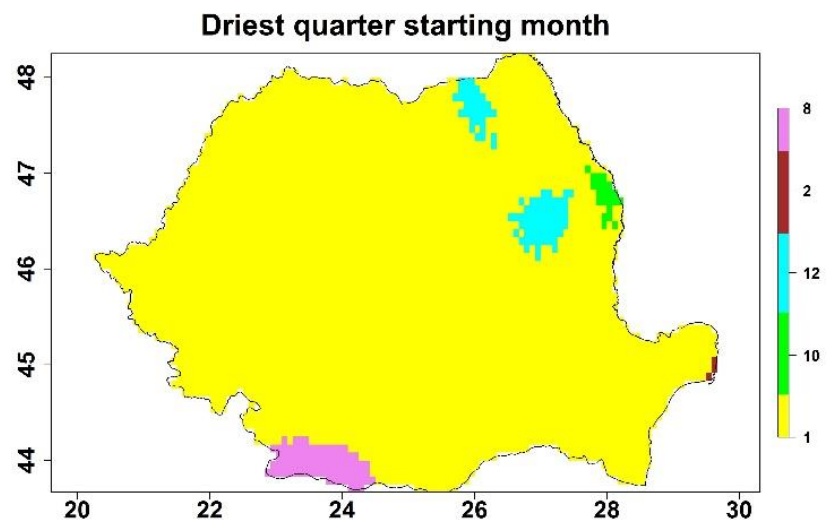

Fig. 9: Current starting month for driest quarter (1 - January, 2 - February, 8 - August, 10 October, 12 - December)

The increase in country average dry quarter temperatures varies greatly $\left(+1.2^{\circ} \mathrm{C}\right.$ to $+24^{\circ} \mathrm{C}$, with high standard deviations Tab. 11) exactly because the driest quarter may change to one with higher average temperatures. It is difficult to interpret the predicted changes of this variable, as in a similar manner to the previous variable, it is unclear to what extent the change is based on an increase of temperatures or a change in the driest quarter. It is also recommended to be cautious in making assessments based on this variable for species distribution modeling. Model agreement is also rather low (Fig. 10, small maps). 

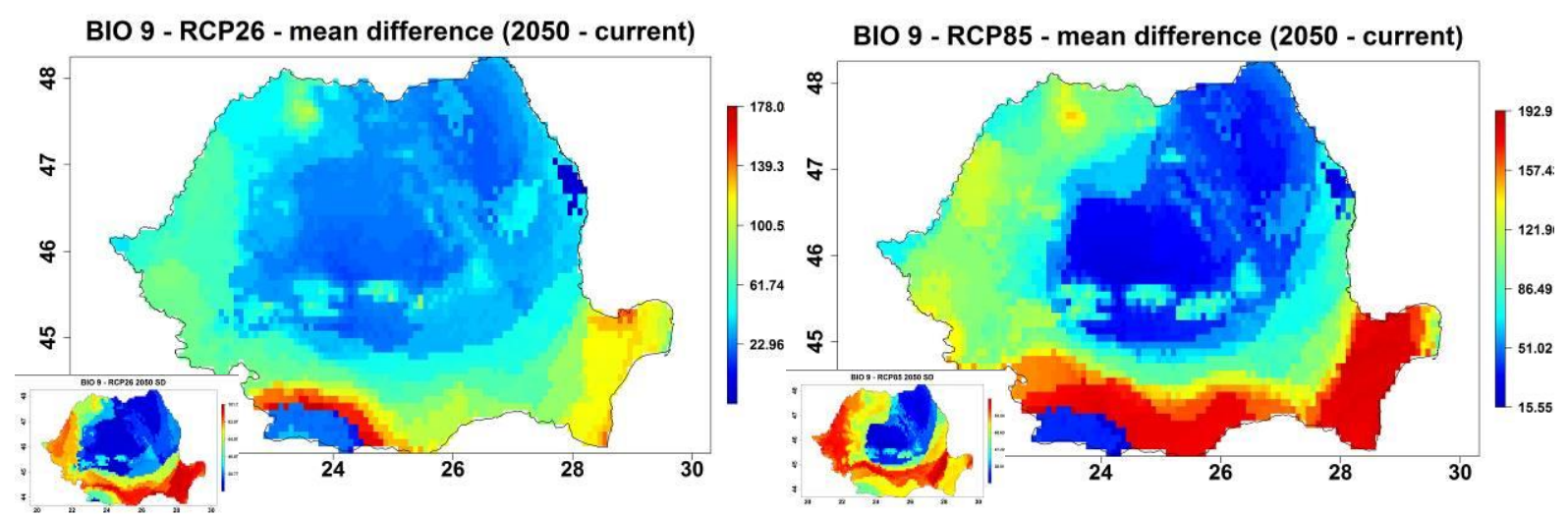

Fig. 10: Average GCM difference between predicted and current values of the mean temperature of the driest quarter in 2050 - RCP26 (left), RCP85 (right). Standard deviations are presented in the lower left corner for both cases (SD values between $25.7-101.1^{\circ} \mathrm{C}$ x 10 for RCP26, SD between $25.7-102.3^{\circ} \mathrm{C} \times$ 10 for RCP85).

\section{BIO10 - Mean Temperature of Warmest Quarter}

The warmest quarter starts currently in June throughout the entire country (months June, July, August). Current values range between $9.4^{\mathrm{O}} \mathrm{C}$ and $22.2^{\mathrm{O}} \mathrm{C}$ at this resolution.

Overall predicted change for the country average temperature of the warmest quarter varies from $+1.06^{\mathrm{O}} \mathrm{C}\left(m g\right.$ GCM, RCP60, 2050) to $+8.79^{\mathrm{O}} \mathrm{C}$ ( $\left.h d \mathrm{GCM}, \mathrm{RCP} 85,2070\right)$ (Tab. 12). The highest increase is generally predicted by the $h d$ GCM (with some exceptions in 2070), while the lowest increase is predicted by the $m g$ GCM $\left(+1.06^{\mathrm{O}} \mathrm{C}\right.$ to $\left.+2.93^{\mathrm{O}} \mathrm{C}\right)$. The standard deviations are small compared to the means, which means there is a low spatial variability of predicted change in each scenario. It is likely there is no significant change in the warmest quarter between predictions.

Table 12: Country average (and standard deviation) of predicted differences for each GCM-RCP-year combination (units: ${ }^{\circ} \mathbf{C} \times 10$ ); minimum and maximum values for each row are highlighted.

\begin{tabular}{|c|c|c|c|c|c|c|c|c|c|c|c|c|}
\hline Year & RCP & bc & cc & gs & hd & he & ip & mc & mg & mi & $\mathbf{m r}$ & no \\
\hline \multirow[t]{8}{*}{2050} & $\mathrm{RCP} 26$ & 24.0 & 23.3 & 14.6 & 43.3 & 37.1 & 29.3 & 36.1 & 11.4 & 38.0 & 42.5 & 27.8 \\
\hline & SD & 1.2 & 0.9 & 0.5 & 4.5 & 2.9 & 1.9 & 1.0 & 1.2 & 6.5 & 6.5 & 1.1 \\
\hline & RCP45 & 30.7 & 27.9 & 22.3 & 53.7 & 46.1 & 31.2 & 38.3 & 15.9 & 38.0 & 43.3 & 30.9 \\
\hline & SD & 2.0 & 0.9 & 0.8 & 6.0 & 4.4 & 1.1 & 1.4 & 1.1 & 4.4 & 4.2 & 1.2 \\
\hline & RCP60 & 31.0 & 27.2 & 22.0 & 45.7 & 42.6 & 29.6 & 33.1 & 10.6 & 34.3 & 40.2 & 26.1 \\
\hline & SD & 1.0 & 1.1 & 0.9 & 5.4 & 4.0 & 1.1 & 0.9 & 1.7 & 3.0 & 2.6 & 0.7 \\
\hline & RCP85 & 42.3 & 39.3 & 25.9 & 67.4 & 55.0 & 38.3 & 45.3 & 19.8 & 51.3 & 55.8 & 38.6 \\
\hline & SD & 1.8 & 1.7 & 0.8 & 9.1 & 5.9 & 1.4 & 1.2 & 1.5 & 6.5 & 6.3 & 1.2 \\
\hline \multirow[t]{8}{*}{2070} & RCP26 & 20.6 & 25.8 & 14.5 & 36.8 & 36.9 & 27.6 & 37.0 & 11.9 & 37.4 & 38.7 & 30.3 \\
\hline & SD & 0.7 & 2.7 & 0.7 & 2.5 & 3.1 & 1.1 & 1.3 & 1.1 & 5.1 & 4.7 & 2.0 \\
\hline & RCP45 & 32.6 & 33.2 & 26.5 & 66.6 & 51.5 & 36.8 & 43.0 & 15.8 & 50.2 & 54.4 & 40.8 \\
\hline & SD & 1.6 & 1.3 & 1.1 & 7.4 & 4.4 & 1.2 & 1.7 & 1.8 & 7.2 & 5.8 & 1.8 \\
\hline & RCP60 & 39.7 & 34.0 & 25.2 & 54.5 & 57.4 & 37.1 & 45.2 & 19.1 & 51.8 & 50.0 & 37.5 \\
\hline & SD & 1.8 & 1.0 & 0.9 & 5.3 & 5.9 & 1.9 & 2.0 & 1.2 & 5.3 & 4.9 & 0.9 \\
\hline & RCP85 & 53.5 & 53.3 & 35.9 & 87.9 & 80.8 & 56.9 & 57.6 & 29.3 & 69.0 & 74.2 & 52.5 \\
\hline & SD & 3.0 & 2.2 & 1.5 & 10.7 & 9.1 & 2.8 & 1.6 & 1.4 & 5.7 & 7.3 & 1.7 \\
\hline
\end{tabular}




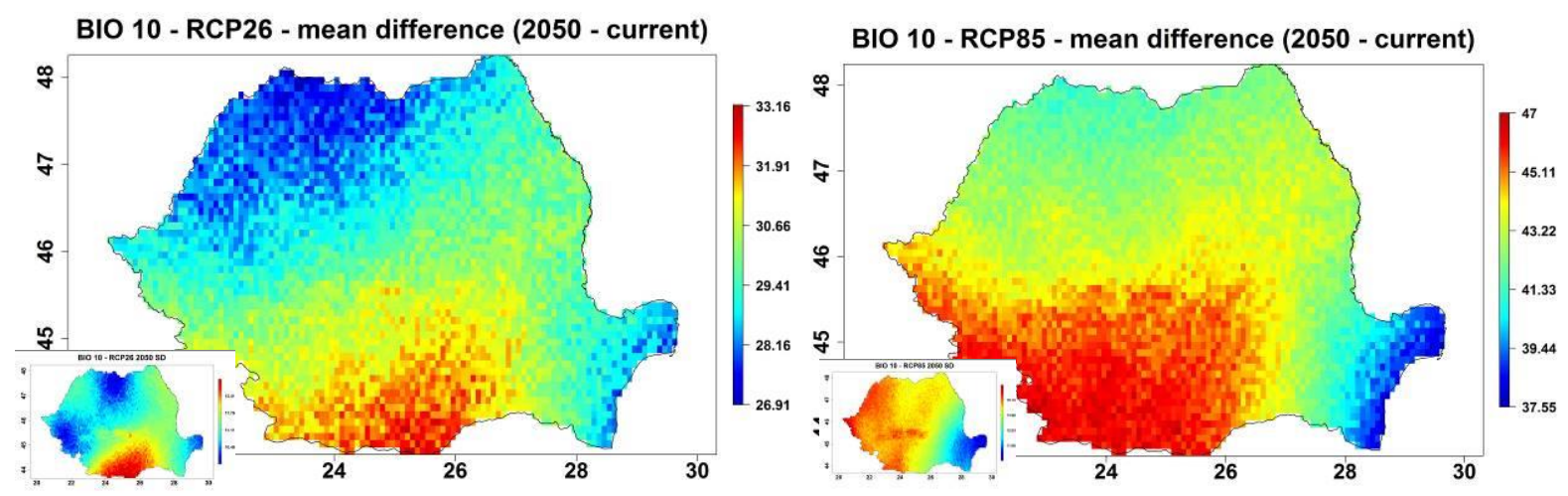

Fig. 11: Average GCM difference between predicted and current values of the mean temperature of the warmest quarter in 2050 - RCP26 (left), RCP85 (right). Standard deviations are presented in the lower left corner for both cases (SD values between $10.34-12.99^{\circ} \mathrm{C}$ x 10 for RCP26, SD between $11.48-16.23^{\circ} \mathrm{C}$ x 10 for RCP85).

In regards to the spatial agreement of GCM models, there is an expected higher increase in the southern part of Romania, and a lower increase in the north and near the Black Sea (Fig. 11, large maps). Model agreement is generally higher for areas with a lower predicted increase (Fig. 11, small maps).

\section{BIO11 - Mean Temperature of Coldest Quarter}

The coldest quarter starts currently in December all over the country (months December, January, February). Current values range between $-6.8^{\mathrm{O}} \mathrm{C}$ and $2.6^{\mathrm{O}} \mathrm{C}$ at this resolution.

Table 13: Country average (and standard deviation) of predicted differences for each GCM-RCP-year combination (units: ${ }^{\circ} \mathbf{C} \mathbf{x} 10$ ); minimum and maximum values for each row are highlighted.

\begin{tabular}{|c|c|c|c|c|c|c|c|c|c|c|c|c|}
\hline Year & RCP & bc & cc & gs & hd & he & ip & mc & mg & mi & $\mathbf{m r}$ & no \\
\hline \multirow[t]{8}{*}{2050} & RCP26 & 12.0 & 11.9 & 16.5 & 43.4 & 30.8 & 40.9 & 27.5 & 10.3 & 38.1 & 23.1 & 16.6 \\
\hline & SD & 0.7 & 0.9 & 1.1 & 4.8 & 2.4 & 5.2 & 1.6 & 1.5 & 1.5 & 1.4 & 1.2 \\
\hline & RCP45 & 18.6 & 15.9 & 22.8 & 38.3 & 36.5 & 42.0 & 27.4 & 11.7 & 29.4 & 24.4 & 29.0 \\
\hline & SD & 1.3 & 0.8 & 1.5 & 3.9 & 3.2 & 5.1 & 2.0 & 1.4 & 1.7 & 1.3 & 2.5 \\
\hline & RCP60 & 22.7 & 14.2 & 25.9 & 46.0 & 35.7 & 42.3 & 22.3 & 22.5 & 34.7 & 29.0 & 22.7 \\
\hline & SD & 2.2 & 0.8 & 1.5 & 4.7 & 3.0 & 4.6 & 1.3 & 1.9 & 1.6 & 1.6 & 1.3 \\
\hline & RCP85 & 23.9 & 21.3 & 29.6 & 49.1 & 42.0 & 51.2 & 38.2 & 19.9 & 39.8 & 33.2 & 22.7 \\
\hline & SD & 1.7 & 1.2 & 1.7 & 5.2 & 3.3 & 5.5 & 2.4 & 1.7 & 1.4 & 1.6 & 1.3 \\
\hline \multirow[t]{8}{*}{2070} & RCP26 & 16.2 & 11.7 & 15.7 & 33.1 & 34.5 & 40.6 & 31.6 & 17.8 & 33.0 & 24.3 & 21.4 \\
\hline & SD & 1.2 & 0.8 & 1.1 & 5.2 & 2.7 & 4.6 & 2.2 & 1.9 & 1.0 & 1.5 & 2.2 \\
\hline & RCP45 & 26.6 & 19.9 & 27.0 & 49.9 & 43.3 & 49.9 & 39.6 & 19.3 & 33.3 & 32.7 & 24.7 \\
\hline & SD & 2.3 & 1.2 & 1.7 & 4.5 & 3.2 & 6.0 & 2.1 & 1.5 & 1.4 & 1.7 & 1.6 \\
\hline & RCP60 & 30.2 & 22.0 & 26.7 & 42.0 & 50.2 & 55.3 & 38.2 & 22.1 & 40.1 & 35.5 & 27.6 \\
\hline & SD & 2.7 & 1.1 & 1.4 & 4.8 & 3.6 & 6.1 & 2.8 & 2.1 & 2.3 & 1.5 & 2.3 \\
\hline & RCP85 & 38.7 & 30.1 & 39.1 & 65.4 & 58.6 & 69.7 & 48.1 & 41.7 & 46.0 & 47.1 & 39.3 \\
\hline & SD & 2.5 & 1.1 & 1.9 & 5.4 & 3.6 & 7.7 & 2.7 & 2.4 & 1.4 & 2.3 & 1.5 \\
\hline
\end{tabular}



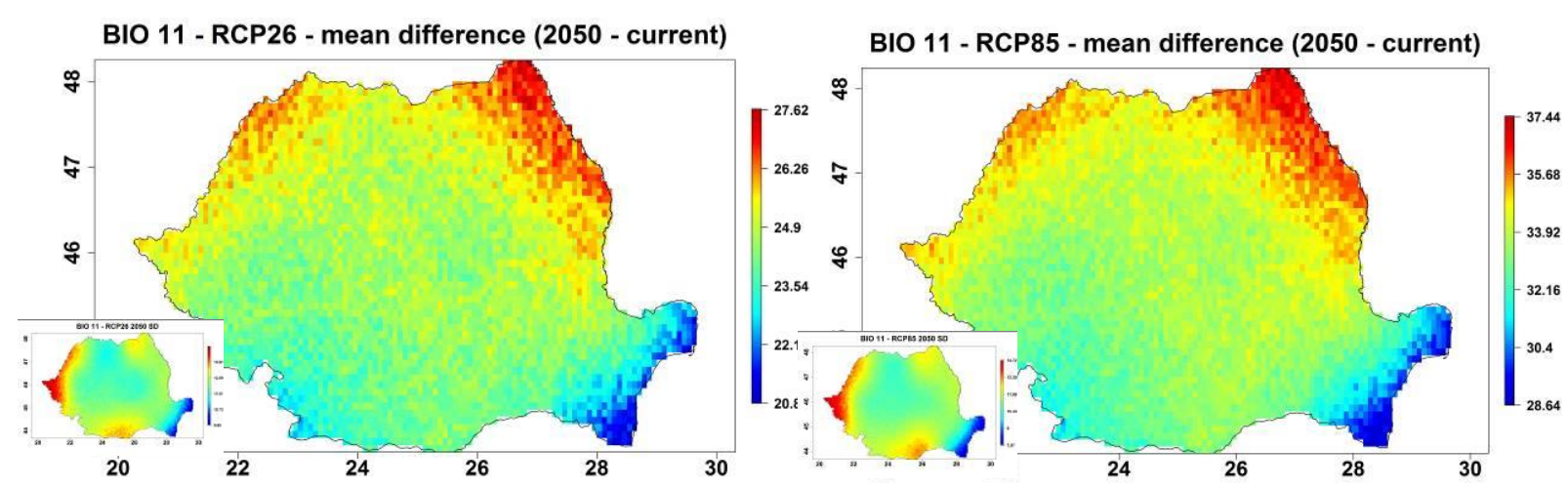

Fig. 12: Average GCM difference between predicted and current values of the mean temperature of the coldest quarter in 2050 - RCP26 (left), RCP85 (right). Standard deviations are presented in the lower left corner for both cases (SD values between $9.65-14.99^{\circ} \mathrm{C}$ x 10 for RCP26, SD between 7.57 $-14.65^{\circ} \mathrm{C}$ x 10 for RCP85).

The predicted country average increase for mean temperature of the coldest quarter varies from $1.03^{\mathrm{O}} \mathrm{C}$ ( $m g$ GCM, RCP26, 2050) to $6.97^{\circ} \mathrm{C}$ (ip GCM, RCP85, 2070) - Tab. 13. In general, the ip $\mathrm{GCM}$ predicts the highest increase (from $4.2^{\mathrm{O}} \mathrm{C}$ to $6.97{ }^{\mathrm{O}} \mathrm{C}$ ), while the $c c$ model predicts to lowest increase (from $1.19^{\mathrm{O}} \mathrm{C}$ to $3.01{ }^{\mathrm{O}} \mathrm{C}$ ).

The mean temperature of the coldest quarter is expected to increase more in the north of Romania, but differences compared to the south are below $1{ }^{\mathrm{O}} \mathrm{C}$ (comparison of averages, Fig. 12, large maps). Models agree the most near the Black Sea, and disagree the most in the west of Romania (Fig. 12, small maps).

\section{BIO12 - Annual Precipitation}

Current values range between $319 \mathrm{~mm}$ and $1091 \mathrm{~mm}$ at this resolution. Precipitation is in general more difficult to model than temperature, as it has a greater spatial variability compared to temperature. This can be observed in the high variation between models in relation to the predictions for Romania (of 88 combinations of GCM, RCP and year, 39 indicate a country average decrease in precipitations, and 49 an increase in precipitations). The increased variability is also seen in the high standard deviation values compared to the means (Tab. 14, Fig. 13 small maps).

Most RCP85 predictions suggest an important decrease in precipitation, but it is not a generally valid trend among GCM models (the RCP85 of $m c$ and $m g$ models predict a country average increase in precipitation). The two mentioned models also predict the highest increase in precipitation variables for Romania overall, while the highest country average decrease is predicted by the $b c$ GCM (values ranging from $-52.9 \mathrm{~mm}$ to $+18.4 \mathrm{~mm}$ - the only positive value is from the year 2070 and RCP26) and for some combinations the hd GCM (between -101 mm and $+16.1 \mathrm{~mm}$ - positive values for both RCP26 combinations).

The high spatial variability and low model agreement make it difficult to draw general conclusions for this variable, but it appears that the south of Romania is predicted to be drier by most GCM and RCP combinations, while the north should be wetter (or less dry, Fig. 13 large maps). 
Table 14: Country average (and standard deviation) of predicted differences for each GCM-RCP-year combination (units: $\mathbf{m m}$ ); minimum and maximum values for each row are highlighted.

\begin{tabular}{|c|c|c|c|c|c|c|c|c|c|c|c|c|}
\hline Year & RCP & bc & cc & gs & hd & he & ip & me & mg & mi & $\mathbf{m r}$ & no \\
\hline \multirow[t]{8}{*}{2050} & RCP26 & -9.6 & 7.3 & 28.6 & 4.2 & 11.5 & -19.1 & 32.6 & 43.5 & -32.2 & 12.2 & 9.9 \\
\hline & SD & 5.8 & 7.7 & 16.0 & 28.9 & 8.6 & 29.6 & 17.1 & 22.7 & 35.9 & 28.0 & 6.3 \\
\hline & RCP45 & -52.9 & 11.3 & 1.4 & -33.5 & -24.6 & 16.7 & 50.0 & 52.8 & 14.8 & 22.3 & -35.3 \\
\hline & SD & 13.1 & 12.3 & 12.4 & 24.3 & 9.3 & 18.3 & 21.0 & 18.5 & 32.6 & 38.1 & 10.8 \\
\hline & RCP60 & -8.5 & 14.3 & 1.1 & -2.9 & -4.5 & 19.5 & 56.1 & 33.3 & 13.2 & 33.7 & 7.4 \\
\hline & SD & 6.0 & 11.4 & 13.8 & 22.7 & 10.7 & 15.9 & 21.4 & 23.1 & 26.6 & 24.3 & 12.0 \\
\hline & RCP85 & -41.8 & -28.1 & -1.9 & -101.8 & -27.2 & -10.2 & 36.6 & 47.8 & -32.1 & 8.3 & -7.8 \\
\hline & SD & 14.5 & 17.6 & 11.7 & 32.6 & 11.8 & 28.1 & 14.8 & 26.0 & 35.6 & 29.1 & 8.0 \\
\hline \multirow[t]{8}{*}{2070} & RCP26 & 18.4 & 4.7 & 7.6 & 16.1 & 8.7 & 16.9 & 21.7 & 33.6 & -13.3 & 40.6 & -4.4 \\
\hline & SD & 8.4 & 12.5 & 8.7 & 16.9 & 11.9 & 19.3 & 16.0 & 23.2 & 35.7 & 20.6 & 5.6 \\
\hline & RCP45 & -7.6 & -8.5 & -14.5 & -76.9 & -5.6 & -6.6 & 48.4 & 41.0 & -19.4 & 26.6 & -41.1 \\
\hline & SD & 10.0 & 10.2 & 13.8 & 26.4 & 10.3 & 19.4 & 25.8 & 21.4 & 43.4 & 33.5 & 9.9 \\
\hline & RCP60 & -43.2 & 7.6 & 5.0 & -4.7 & -15.1 & 16.5 & 26.3 & 64.9 & 10.6 & 38.1 & -25.5 \\
\hline & SD & 12.6 & 12.4 & 13.5 & 27.0 & 11.6 & 18.7 & 21.6 & 38.7 & 41.7 & 33.0 & 14.5 \\
\hline & RCP85 & -40.7 & -21.1 & -46.6 & -92.7 & -60.2 & -62.6 & 37.6 & 98.2 & 12.9 & -6.8 & -2.2 \\
\hline & SD & 11.6 & 15.6 & 15.7 & 30.2 & 18.5 & 34.6 & 17.2 & 45.1 & 41.5 & 28.8 & 9.9 \\
\hline
\end{tabular}

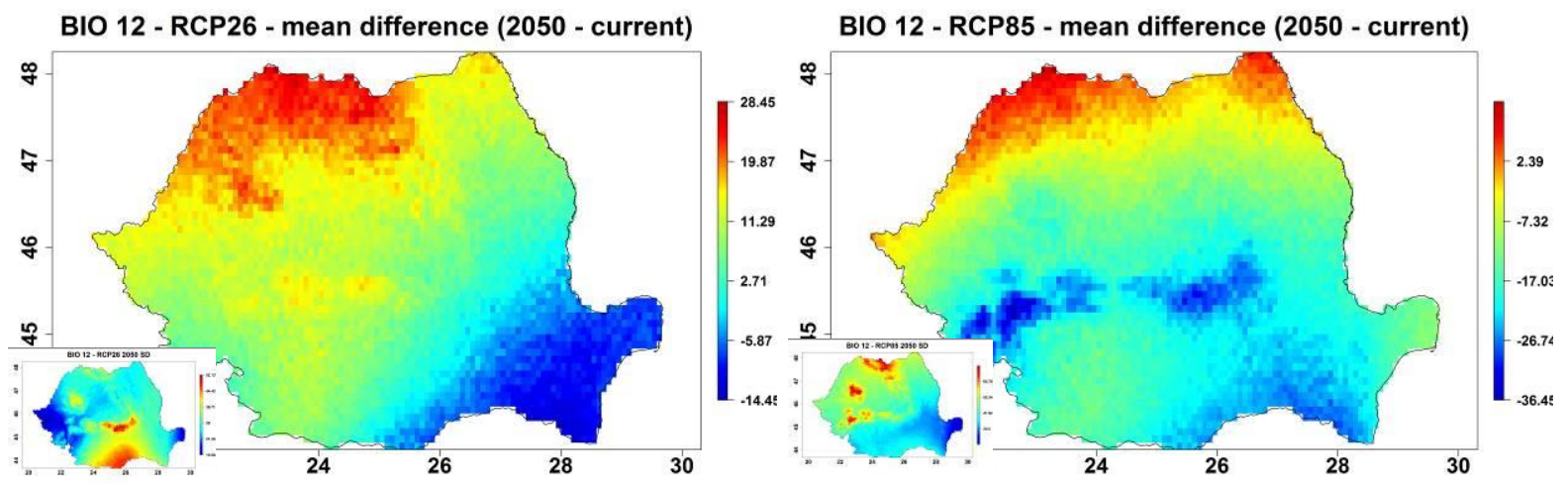

Fig. 13: Average GCM difference between predicted and current values of the annual precipitation in 2050 - RCP26 (left), RCP85 (right). Standard deviations are presented in the lower left corner for both cases (SD values between 13.58-52.1 mm for RCP26, SD between $26.2-82.1 \mathrm{~mm}$ for RCP85).

\section{BIO13 - Precipitation of Wettest Month}

Based on averages for the period 1960-2000, the wettest month is June in almost the entire country (with the exception of very small areas near the Black Sea, where September or November are the wettest months). Current values range between 35 and $163 \mathrm{~mm}$ at this resolution.

Predicted variability between GCMs in the case of the wettest month is rather low, with country average values fluctuating between $-18 \mathrm{~mm}$ ( $g s$ GCM, RCP85, 2070) and $+21.9 \mathrm{~mm}$ ( $m c$ GCM, RCP 60, 2050) - Tab. 15. In many scenarios, the standard deviation is high compared to the mean, which means there is rather high spatial variation of predicted change for this variable. 
Table 15: Country average (and standard deviation) of predicted differences for each GCM-RCP-year combination (units: mm); minimum and maximum values for each row are highlighted.

\begin{tabular}{|c|c|c|c|c|c|c|c|c|c|c|c|c|}
\hline Year & RCP & bc & cc & gs & hd & he & ip & mc & mg & mi & $\mathbf{m r}$ & no \\
\hline \multirow[t]{8}{*}{2050} & RCP26 & -4.2 & 0.1 & 4.3 & 0.4 & 6.6 & -3.4 & 12.3 & 5.6 & -6.5 & 3.3 & 1.6 \\
\hline & SD & 4.6 & 2.4 & 4.1 & 9.7 & 2.7 & 4.2 & 7.0 & 7.2 & 5.8 & 5.5 & 3.5 \\
\hline & RCP45 & -7.4 & -0.2 & -2.6 & -1.2 & -1.5 & 2.0 & 13.1 & 10.1 & 3.6 & 3.5 & -2.2 \\
\hline & SD & 7.0 & 3.9 & 4.3 & 10.1 & 2.6 & 3.7 & 4.3 & 8.9 & 9.0 & 5.2 & 3.7 \\
\hline & RCP60 & 4.3 & 1.2 & -1.9 & 7.1 & -0.8 & -3.0 & 21.9 & 3.8 & -1.2 & 9.8 & 0.1 \\
\hline & SD & 2.0 & 4.3 & 4.2 & 10.4 & 4.5 & 3.8 & 6.4 & 6.2 & 9.7 & 4.7 & 2.3 \\
\hline & RCP85 & -5.5 & -3.4 & -3.3 & -14.9 & -6.6 & 0.0 & 2.3 & 4.5 & 0.6 & 13.3 & -2.0 \\
\hline & SD & 3.4 & 3.5 & 6.4 & 8.5 & 2.8 & 6.5 & 3.8 & 7.8 & 5.6 & 6.5 & 2.4 \\
\hline \multirow[t]{8}{*}{2070} & RCP26 & 4.2 & 2.5 & -2.8 & 7.1 & 7.6 & 9.5 & 6.7 & 8.7 & -8.5 & 6.8 & 8.4 \\
\hline & SD & 8.0 & 2.7 & 4.0 & 8.5 & 3.0 & 3.6 & 4.7 & 7.7 & 8.0 & 8.1 & 3.3 \\
\hline & RCP45 & -0.7 & -1.2 & -8.2 & -13.5 & -0.9 & 0.8 & 9.6 & 2.5 & -3.0 & 4.3 & -6.1 \\
\hline & SD & 4.4 & 2.9 & 4.5 & 8.7 & 2.2 & 3.7 & 2.9 & 7.8 & 9.2 & 4.0 & 2.1 \\
\hline & RCP60 & -7.2 & -0.6 & -4.4 & -0.6 & -5.1 & -3.1 & -2.3 & 12.1 & 0.9 & 13.4 & 1.0 \\
\hline & SD & 3.0 & 4.3 & 4.7 & 8.6 & 3.9 & 5.3 & 4.1 & 9.3 & 12.2 & 12.3 & 3.1 \\
\hline & RCP85 & -10.3 & -6.5 & -18.0 & -16.5 & -11.2 & -12.5 & 3.4 & 7.2 & -1.0 & 3.6 & 1.2 \\
\hline & SD & 4.4 & 5.0 & 6.0 & 10.1 & 7.5 & 6.3 & 3.3 & 8.2 & 8.9 & 8.1 & 4.6 \\
\hline
\end{tabular}
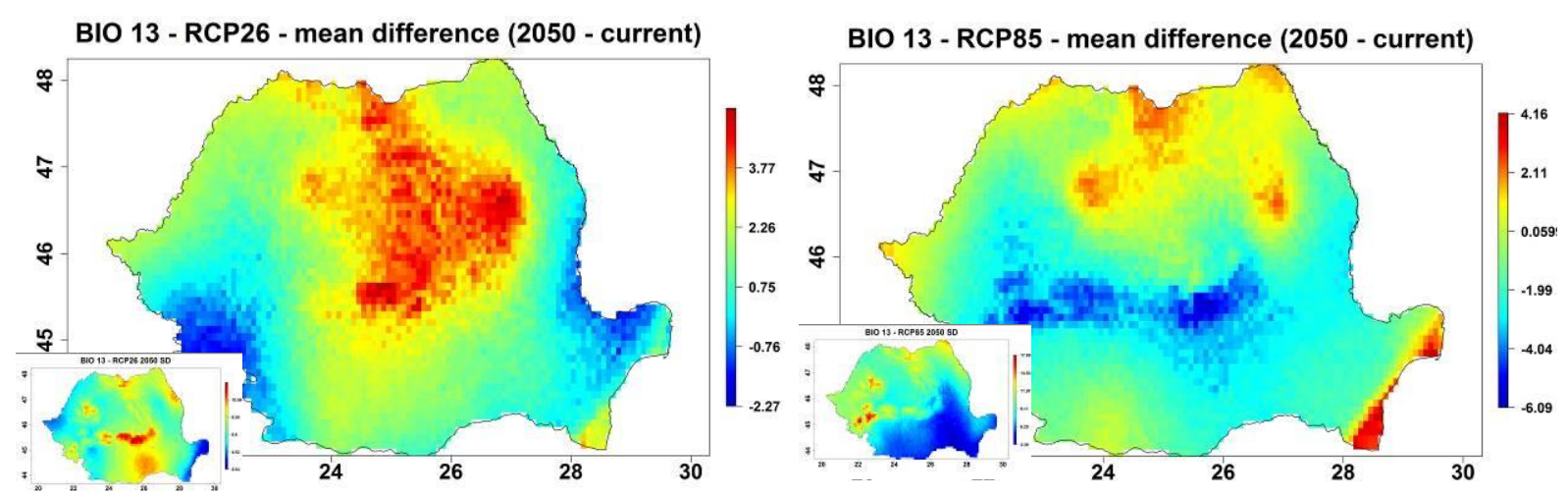

Fig. 14: Average GCM difference between predicted and current values for the precipitation of the wettest month in 2050 - RCP26 (left), RCP85 (right). Standard deviations are presented in the lower left corner for both cases (SD values between 2.64-12.48 mm for RCP26, SD between 3.39-17.6 mm for $\mathrm{RCP} 85)$.

The spatial variability of the average change in BIO13 is modest (Fig. 14, large maps). It is even more difficult to distinguish a clear trend as it differs for each RCP scenario. What is clear, is that GCM models disagreement is rather high compared to the mean, and it is higher for the mountain regions (Fig. 14, small maps).

BIO14 - Precipitation of Driest Month (units: mm)

There is high variability as to which is the driest month in the territory of Romania. January, February and March are the most widespread, but there are also regions where October or even September is the driest month (Fig. 15). Current values range between 17 and $58 \mathrm{~mm}$ at this resolution. 


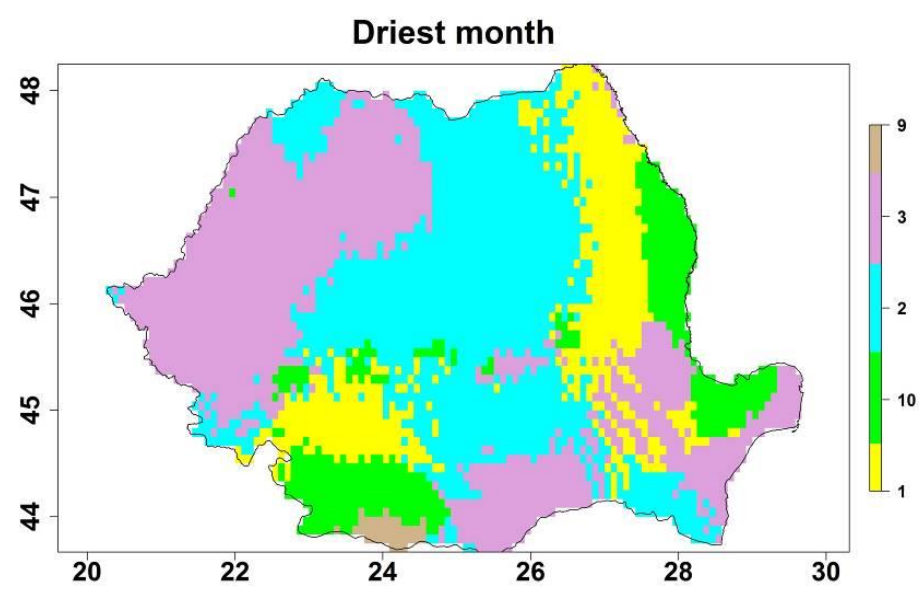

Fig. 15: Driest month in Romania (1 - January, 2 - February, 3 - March, 9 - September, 10 - October)

Table 16: Country average (and standard deviation) of predicted differences for each GCM-RCP-year combination (units: $\mathbf{m m}$ ); minimum and maximum values for each row are highlighted.

\begin{tabular}{|c|c|c|c|c|c|c|c|c|c|c|c|c|}
\hline Year & RCP & bc & cc & gs & hd & he & ip & mc & mg & mi & $\mathbf{m r}$ & no \\
\hline \multirow[t]{8}{*}{2050} & $\mathrm{RCP} 26$ & -1.69 & 1.03 & 0.70 & -1.79 & -0.12 & -2.76 & -0.75 & -0.28 & -0.18 & -1.36 & -1.80 \\
\hline & SD & 1.58 & 1.09 & 1.36 & 3.54 & 2.57 & 2.85 & 1.59 & 2.81 & 3.78 & 3.26 & 1.14 \\
\hline & $\mathrm{RCP} 45$ & -2.75 & 0.47 & 0.82 & -6.58 & -2.07 & -2.64 & 0.17 & -5.06 & -1.25 & -0.10 & -6.97 \\
\hline & SD & 1.66 & 1.52 & 1.01 & 6.39 & 5.05 & 1.80 & 3.43 & 3.64 & 4.64 & 2.69 & 1.63 \\
\hline & RCP60 & -2.29 & -0.55 & -0.03 & -3.87 & -1.89 & -2.80 & -1.26 & -4.25 & -1.16 & -0.78 & -1.95 \\
\hline & SD & 2.19 & 1.53 & 1.85 & 5.09 & 3.34 & 1.64 & 2.22 & 2.78 & 3.52 & 2.37 & 1.60 \\
\hline & RCP85 & -3.07 & -0.15 & -0.03 & -9.56 & -2.49 & -7.46 & 1.20 & -2.42 & -5.35 & -2.57 & -3.53 \\
\hline & SD & 5.54 & 1.64 & 1.24 & 6.87 & 3.73 & 2.57 & 3.03 & 3.68 & 6.20 & 3.36 & 2.53 \\
\hline \multirow[t]{8}{*}{2070} & $\mathrm{RCP} 26$ & -1.26 & -0.02 & 1.23 & -0.76 & 0.99 & -2.68 & 0.49 & -2.38 & -0.17 & 1.16 & -2.89 \\
\hline & SD & 1.75 & 1.54 & 1.57 & 3.73 & 2.56 & 1.75 & 2.16 & 2.33 & 3.36 & 2.73 & 1.95 \\
\hline & RCP45 & -3.28 & -0.04 & 0.51 & -11.95 & 0.21 & -2.00 & 0.85 & -0.39 & -1.68 & -1.33 & -2.46 \\
\hline & SD & 2.09 & 2.71 & 1.23 & 7.35 & 4.84 & 2.34 & 3.04 & 2.80 & 3.92 & 3.59 & 1.46 \\
\hline & RCP60 & -1.76 & 1.53 & 0.95 & -5.33 & 0.14 & -1.58 & -1.22 & -2.14 & 0.34 & -1.52 & -1.91 \\
\hline & SD & 3.48 & 1.48 & 0.82 & 6.13 & 3.87 & 2.85 & 1.86 & 2.71 & 3.05 & 1.93 & 1.10 \\
\hline & RCP85 & -3.66 & -1.01 & -0.31 & -12.64 & -6.80 & -4.04 & 2.84 & 0.80 & -2.10 & -3.60 & -3.09 \\
\hline & SD & 3.46 & 2.52 & 1.40 & 8.12 & 7.20 & 2.32 & 2.49 & 4.62 & 6.16 & 3.24 & 1.87 \\
\hline
\end{tabular}

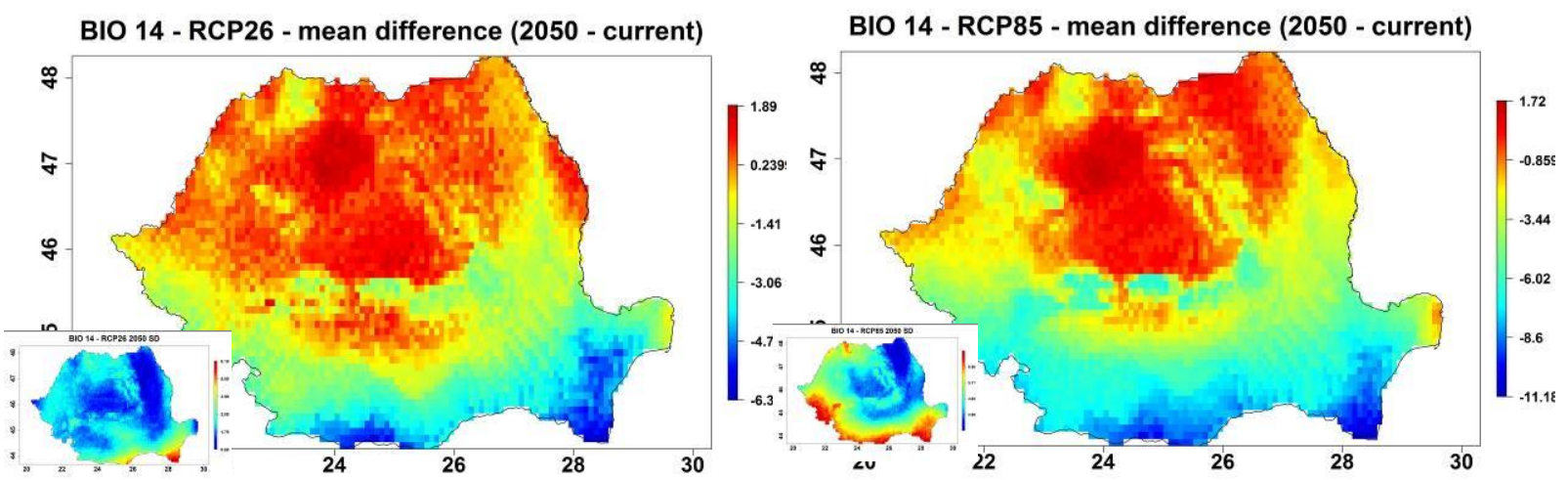

Fig. 16: Average GCM difference between predicted and current values for the precipitation of the driest month in 2050 - RCP26 (left), RCP85 (right). Standard deviations are presented in the lower left corner for both cases (SD values between $0.69-6.15 \mathrm{~mm}$ for RCP26, SD between $2.8-7.3 \mathrm{~mm}$ for RCP85). 
For the driest month, predicted differences compared to present are even smaller, with overall country average variation between $-12.6 \mathrm{~mm}$ ( $h d$ GCM, RCP85, 2070) and $+2.84 \mathrm{~mm}$ ( $m c$ GCM, RCP60, 2070). The gs model indicates in general the highest increase in precipitations / the smallest decrease in precipitations (it also has negative values for some GCM-RCP combinations), while the $h d$ model indicates usually the highest decrease (Tab. 16). Spatial variability of predicted average change is also high (Fig. 16, small maps), but a general trend can be inferred - a decrease in precipitations in the south of Romania (even if small, Fig. 16, large maps).

\section{BIO15 - Precipitation Seasonality (Coefficient of Variation)}

Based on data from 1960 to 2000, BIO15 has values between 13 and 54 within Romania at this resolution. Higher values indicate higher variability of precipitation. Values are higher in the Carpathians, in the Transylvanian Plateau and in the region of Moldova (except southern Moldova), and are lower in the west and south.

Table 17: Country average (and standard deviation) of predicted differences for each GCM-RCP-year combination (units: percent); minimum and maximum values for each row are highlighted.

\begin{tabular}{|c|c|c|c|c|c|c|c|c|c|c|c|c|}
\hline Year & RCP & bc & cc & gs & hd & he & ip & mc & mg & mi & mr & no \\
\hline \multirow[t]{8}{*}{2050} & RCP26 & -2.7 & -2.1 & -0.1 & -1.2 & 0.3 & -0.2 & 0.8 & 1.3 & -4.5 & -0.1 & 1.6 \\
\hline & SD & 1.7 & 1.9 & 1.3 & 6.4 & 2.8 & 2.7 & 1.3 & 2.5 & 3.3 & 4.4 & 0.9 \\
\hline & RCP45 & -1.7 & -1.3 & -2.0 & 2.4 & -0.4 & 1.8 & 2.2 & 1.4 & -0.6 & 2.0 & 3.8 \\
\hline & SD & 3.6 & 1.4 & 1.4 & 7.6 & 3.8 & 2.2 & 2.4 & 2.4 & 4.4 & 2.1 & 3.1 \\
\hline & RCP60 & 2.7 & -0.3 & -2.3 & 3.1 & -0.6 & 0.4 & 5.3 & 2.6 & -3.3 & 3.6 & 0.8 \\
\hline & SD & 2.7 & 1.4 & 1.7 & 4.8 & 5.0 & 2.4 & 1.2 & 2.2 & 4.4 & 2.9 & 2.2 \\
\hline & RCP85 & -1.2 & -3.2 & -2.0 & -2.7 & -3.3 & 4.0 & -1.7 & 3.1 & 4.4 & 4.6 & 0.3 \\
\hline & SD & 4.3 & 1.9 & 1.9 & 7.0 & 4.4 & 4.7 & 2.5 & 3.3 & 4.3 & 3.2 & 1.4 \\
\hline \multirow[t]{8}{*}{2070} & RCP26 & 2.1 & -0.5 & -2.9 & 0.2 & 0.4 & 3.0 & -1.0 & 4.5 & -5.7 & 0.8 & 4.3 \\
\hline & SD & 1.9 & 1.1 & 1.1 & 4.2 & 3.2 & 1.2 & 2.2 & 2.5 & 3.4 & 5.2 & 2.3 \\
\hline & RCP45 & 1.8 & -1.9 & -4.3 & -1.7 & -4.3 & 1.3 & 1.9 & 0.3 & -1.5 & 0.6 & -2.8 \\
\hline & SD & 2.7 & 1.4 & 1.5 & 5.7 & 4.6 & 2.8 & 2.2 & 2.4 & 3.2 & 4.1 & 2.0 \\
\hline & RCP60 & -3.7 & -3.3 & -3.8 & -1.0 & -4.2 & 0.9 & -2.3 & 4.6 & -0.4 & -0.1 & 0.2 \\
\hline & SD & 3.1 & 2.1 & 1.9 & 4.7 & 5.8 & 2.7 & 2.8 & 2.1 & 5.4 & 5.7 & 2.7 \\
\hline & RCP85 & -1.8 & -3.8 & -8.9 & -0.3 & -3.1 & -1.1 & -2.2 & -1.0 & -1.9 & 2.8 & -0.2 \\
\hline & SD & 4.3 & 3.3 & 2.3 & 10.2 & 6.3 & 3.1 & 2.2 & 2.1 & 5.1 & 3.6 & 2.3 \\
\hline
\end{tabular}

Precipitation seasonality is predicted by most combinations of models, RCPs and years to decrease (country average of 50 out of 88 combinations, Tab. 17), but the decrease is rather small. Analyzing the spatial variation of change in precipitation seasonality, in general a slight decrease is predicted in the regions where it is now high, as well as an increase in regions where it is low, resulting in a more homogenous distribution off this variable (Fig. 17, large maps). 

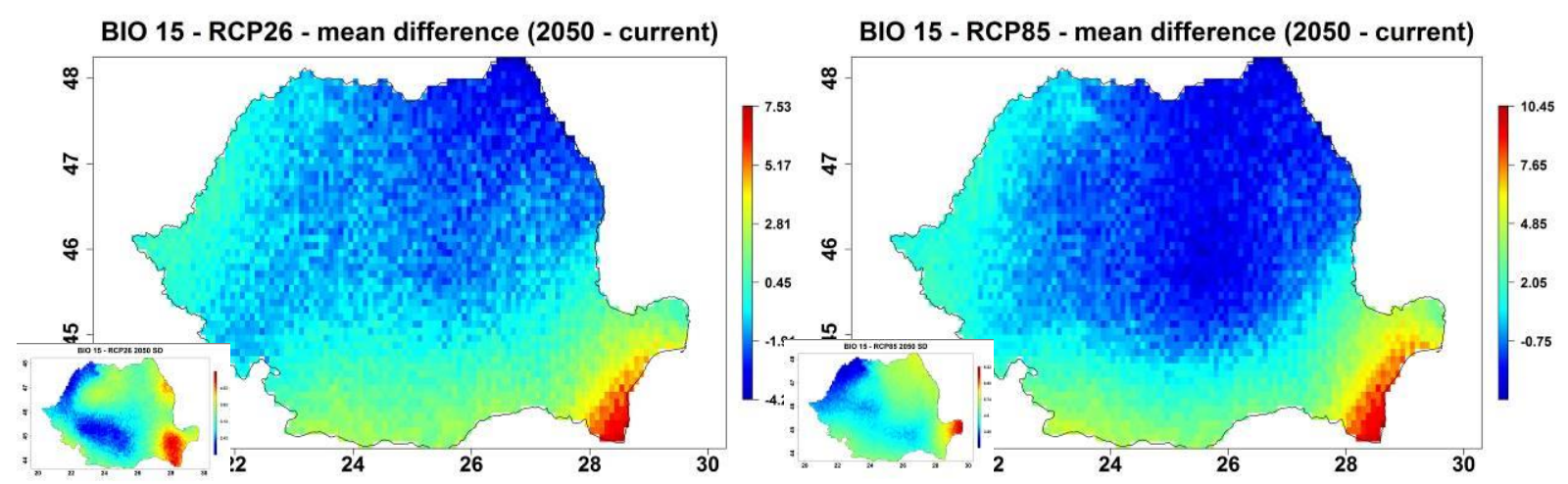

Fig. 17: Average GCM difference between predicted and current values of the precipitation seasonality in 2050 - RCP26 (left), RCP85 (right). Standard deviations are presented in the lower left corner for both cases (SD values between $2.3-5.15 \%$ for RCP26, SD between 3.05-8.2 \% for RCP85).

\section{BIO16 - Precipitation of Wettest Quarter}

Precipitation of wettest quarter has values between 95 and $424 \mathrm{~mm}$ at this resolution (based on data from 1960 to 2000).

Table 18: Country average (and standard deviation) of predicted differences for each GCM-RCP-year combination (units: mm); minimum and maximum values for each row are highlighted.

\begin{tabular}{l}
$\begin{array}{l}\text { Year } \\
2050\end{array}$ \\
\cline { 2 - 6 }
\end{tabular}

Change in country average for precipitation of wettest quarter ranges between $-52.9 \mathrm{~mm}$ (hd GCM, RCP85, 2050) and + 41.4 mm (mg GCM, RCP60, 2050), but most country averages are lower than these extremes. Although most RCP85 scenarios predict a decrease of precipitations in the wettest quarter, some indicate an increase (GCMs $m g, m c, m i$ ). The $m g$ and $m c$ scenarios are the ones with the highest increase indicated for this parameter in all GCM-RCPyear combinations. In contrast, the $h d$ GCM displays generally a decrease in precipitations of the wettest quarter (Tab. 18). Spatial variability of predicted change (standard deviation, Tab. 18) is high compared to the mean for most GCM-RCP-year combinations. 

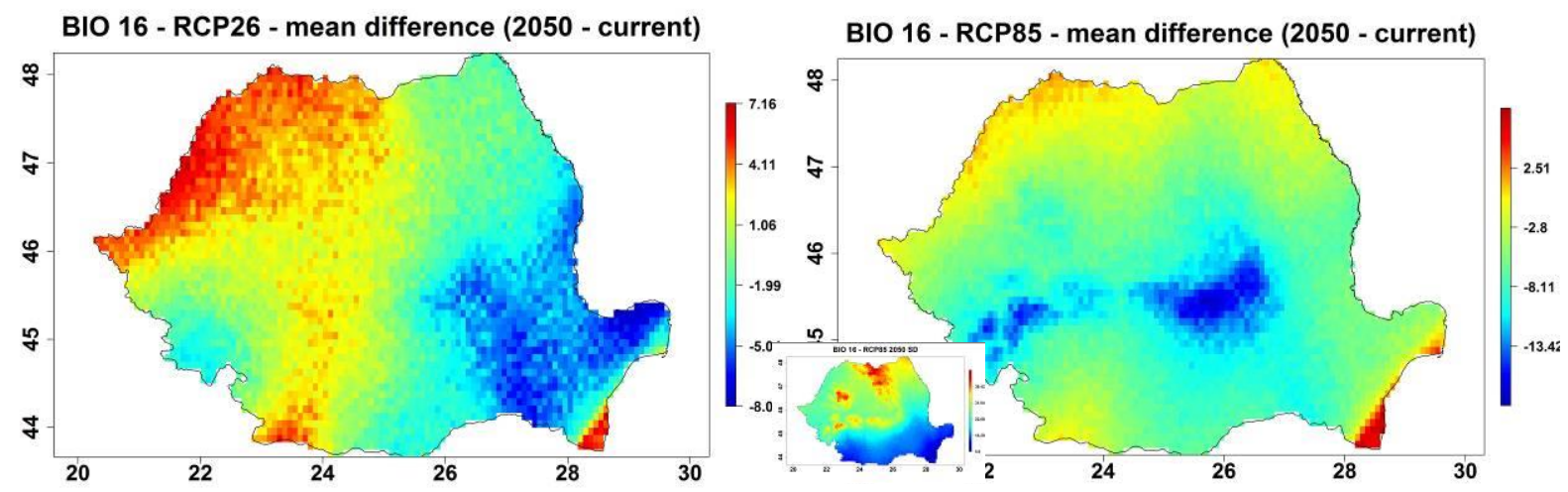

Fig. 18: Average GCM difference between predicted and current values for the precipitation of the wettest quarter in 2050 - RCP26 (left), RCP85 (right). Standard deviations are presented in the lower left corner for both cases (SD values between 4.65-27.87 $\mathrm{mm}$ for RCP26, SD between 5.9 - $47.72 \mathrm{~mm}$ for RCP85).

As mentioned for the BIO8 variable, the starting month of the wettest quarter probably changes in the future, making the predictions based on this parameter difficult to assess. Based on average values, there is no common trend for both RCP scenarios presented (Fig. 18, large maps). Model disagreement is high for this variable (Fig. 18, small maps).

\section{BIO17 - Precipitation of Driest Quarter}

Based on data from 1960 to 2000, the driest quarter has values between 63 and $195 \mathrm{~mm}$ at this resolution.

The predictions for country average precipitations of driest quarter vary less, from -26.1 $\mathrm{mm}$ (hd GCM, RCP85, 2070) to + $14.4 \mathrm{~mm}$ (mg GCM, RCP85, 2070), with most scenarios predicting less change (Tab. 19). There is no clear GCM to predict constant increase in all GCM - RCP - year combinations. The driest quarter starting month also varies most likely in the future, making this a more difficult variable to interpret.

Table 19: Country average (and standard deviation) of predicted differences for each GCM-RCP-year combination (units: $\mathbf{m m}$ ); minimum and maximum values for each row are highlighted.

\begin{tabular}{|c|c|c|c|c|c|c|c|c|c|c|c|c|}
\hline Year & $\mathbf{R C P}$ & bc & cc & gs & hd & he & ip & mc & mg & mi & $\mathbf{m r}$ & no \\
\hline \multirow[t]{8}{*}{2050} & RCP26 & 3.5 & 5.1 & 3.2 & 6.7 & 8.1 & -6.7 & 4.9 & 3.9 & 2.3 & 5.3 & -0.2 \\
\hline & $\mathrm{SD}$ & 2.3 & 2.0 & 2.4 & 12.4 & 5.4 & 8.3 & 2.8 & 6.1 & 10.5 & 5.1 & 1.7 \\
\hline & $\mathrm{RCP} 45$ & -3.2 & 7.0 & 2.7 & -4.2 & 1.3 & -8.4 & 9.5 & 8.2 & 3.5 & 1.1 & -8.8 \\
\hline & SD & 3.8 & 4.0 & 2.0 & 10.4 & 9.8 & 4.8 & 4.7 & 6.4 & 12.3 & 6.1 & 5.5 \\
\hline & RCP60 & -1.9 & 4.9 & 2.9 & -0.8 & 4.6 & -1.0 & 7.2 & -0.5 & 10.4 & 4.3 & 0.0 \\
\hline & SD & 4.3 & 2.4 & 2.3 & 10.6 & 6.9 & 2.7 & 4.6 & 5.8 & 8.9 & 4.2 & 2.5 \\
\hline & RCP85 & 2.7 & 4.2 & 1.9 & -13.1 & 3.6 & -11.9 & 11.2 & 6.1 & -6.4 & -0.1 & 1.3 \\
\hline & SD & 10.6 & 4.1 & 3.4 & 16.3 & 10.2 & 5.8 & 5.9 & 8.9 & 15.3 & 6.0 & 5.6 \\
\hline \multirow[t]{8}{*}{2070} & RCP26 & 3.8 & 3.8 & 6.4 & 7.4 & 8.7 & -4.4 & 4.1 & -1.5 & 7.4 & 7.5 & -0.5 \\
\hline & SD & 6.1 & 3.6 & 3.2 & 8.2 & 5.8 & 2.8 & 4.9 & 3.2 & 9.0 & 4.6 & 4.2 \\
\hline & RCP45 & -3.8 & 6.4 & 2.1 & -9.9 & 8.6 & -4.8 & 9.9 & 5.6 & 0.8 & -2.1 & 1.7 \\
\hline & $\mathrm{SD}$ & 1.9 & 4.2 & 2.7 & 14.8 & 11.3 & 6.5 & 7.1 & 4.5 & 8.9 & 7.5 & 3.9 \\
\hline & RCP60 & 1.7 & 8.7 & 3.7 & 2.6 & 6.8 & -3.3 & 1.9 & 4.7 & 4.5 & 4.6 & 0.8 \\
\hline & SD & 5.9 & 3.1 & 1.6 & 11.4 & 9.1 & 7.2 & 4.0 & 7.1 & 7.9 & 4.3 & 3.6 \\
\hline & RCP85 & -4.6 & 8.0 & 2.9 & -26.1 & -9.8 & -10.4 & 11.8 & 14.4 & 8.8 & -4.6 & 5.7 \\
\hline & SD & 13.2 & 5.2 & 2.8 & 21.8 & 21.7 & 7.5 & 6.1 & 11.1 & 11.4 & 6.2 & 2.4 \\
\hline
\end{tabular}




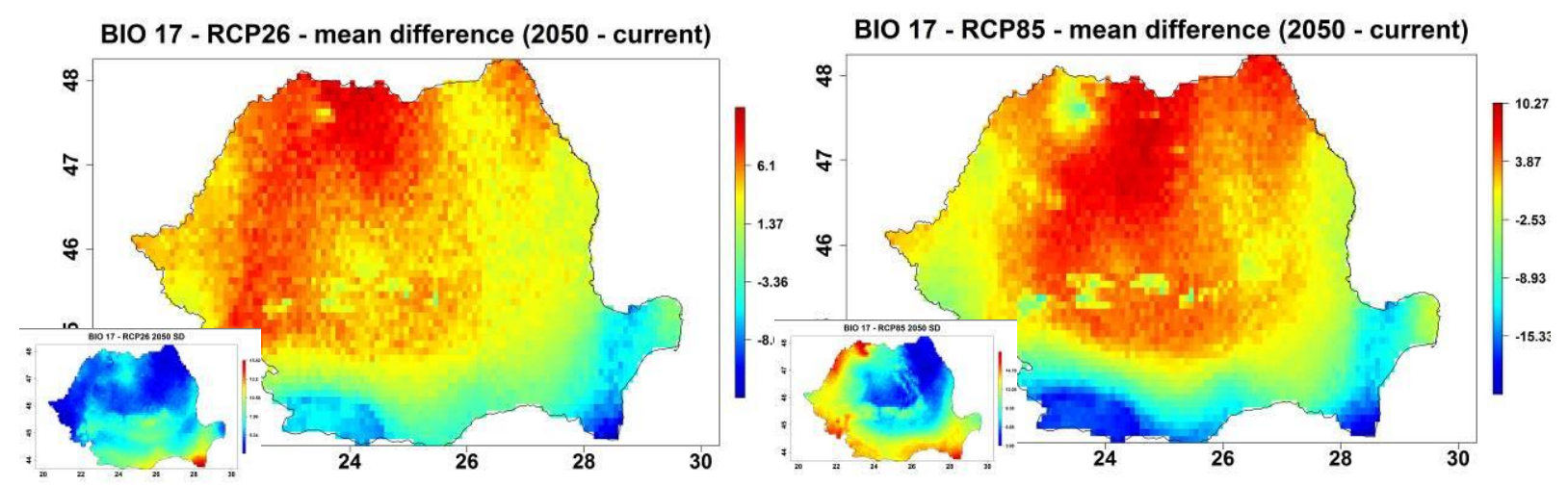

Fig. 19: Average GCM difference between predicted and current values for the precipitation of the driest quarter in 2050 - RCP26 (left), RCP85 (right). Standard deviations are presented in the lower left corner for both cases (SD values between 4.9-15.8 mm for RCP26, SD between 3.98-17.42 $\mathrm{mm}$ for RCP85).

A spatial trend, even if not very pronounced appears in both investigated cases (RCP26 and RCP85 for 2050, Fig. 19 large maps), with a slight increase in precipitations of the driest quarter in the northern and central parts of Romania, and a decrease in the south (where models tend also to disagree more - Fig. 19 small maps). Overall model disagreement is high.

\section{BIO18 - Precipitation of Warmest Quarter}

Precipitation of the warmest quarter varies between 93 and $408 \mathrm{~mm}$ at this resolution.

Table 20: Country average (and standard deviation) of predicted differences for each GCM-RCP-year combination (units: mm); minimum and maximum values for each row are highlighted.

\begin{tabular}{|c|c|c|c|c|c|c|c|c|c|c|c|c|}
\hline Year & $\mathbf{R C P}$ & bc & cc & gs & hd & he & ip & mc & mg & mi & $\mathbf{m r}$ & no \\
\hline \multirow[t]{8}{*}{2050} & RCP26 & -11.6 & -9.6 & 12.9 & -53.9 & -19.7 & -13.4 & 10.4 & 16.6 & -45.9 & -32.8 & 0.4 \\
\hline & SD & 4.9 & 6.9 & 10.0 & 16.7 & 9.1 & 7.8 & 9.1 & 15.0 & 27.9 & 24.1 & 3.8 \\
\hline & RCP45 & -57.0 & -6.3 & -0.9 & -64.0 & -53.9 & 16.4 & 19.9 & 10.8 & -7.1 & -5.3 & -23.6 \\
\hline & SD & 11.4 & 8.5 & 6.9 & 20.5 & 11.0 & 7.2 & 11.5 & 13.6 & 28.1 & 17.6 & 9.4 \\
\hline & RCP60 & -13.1 & 3.8 & -4.8 & -57.3 & -30.2 & 10.9 & 17.5 & 10.6 & -14.4 & -4.0 & -7.4 \\
\hline & SD & 5.8 & 8.2 & 9.7 & 23.6 & 13.3 & 4.7 & 9.6 & 13.1 & 26.7 & 17.5 & 9.0 \\
\hline & RCP85 & -61.7 & -31.0 & -4.0 & -104.4 & -62.8 & 8.4 & 0.7 & 18.6 & -65.7 & -37.1 & -17.4 \\
\hline & SD & 23.9 & 10.9 & 9.7 & 22.5 & 16.2 & 10.8 & 8.0 & 17.4 & 33.8 & 36.1 & 5.2 \\
\hline \multirow[t]{8}{*}{2070} & RCP26 & -12.7 & -3.5 & -2.9 & -29.4 & -22.7 & 5.7 & -0.5 & 19.5 & -42.1 & -9.4 & 2.0 \\
\hline & SD & 17.9 & 9.2 & 4.8 & 15.4 & 9.5 & 8.1 & 7.4 & 15.5 & 26.2 & 22.8 & 7.0 \\
\hline & RCP45 & -28.9 & -6.7 & -13.7 & -99.6 & -44.3 & -0.5 & 15.1 & 9.3 & -31.1 & -17.3 & -40.2 \\
\hline & SD & 9.8 & 8.1 & 7.6 & 27.4 & 10.4 & 7.0 & 7.8 & 14.0 & 31.4 & 22.8 & 9.5 \\
\hline & RCP60 & -47.2 & -8.6 & -2.1 & -57.3 & -54.4 & 1.7 & -15.5 & 24.2 & -14.8 & -0.8 & -31.2 \\
\hline & SD & 18.6 & 10.3 & 7.5 & 18.8 & 14.0 & 7.1 & 15.1 & 25.5 & 30.4 & 22.2 & 10.0 \\
\hline & RCP85 & -55.2 & -27.6 & -31.4 & -124.4 & -91.9 & -26.3 & -4.3 & 20.4 & -33.0 & -9.8 & -25.7 \\
\hline & $\mathrm{SD}$ & 20.1 & 9.6 & 8.7 & 28.2 & 21.4 & 13.6 & 8.8 & 17.6 & 29.2 & 24.2 & 21.1 \\
\hline
\end{tabular}



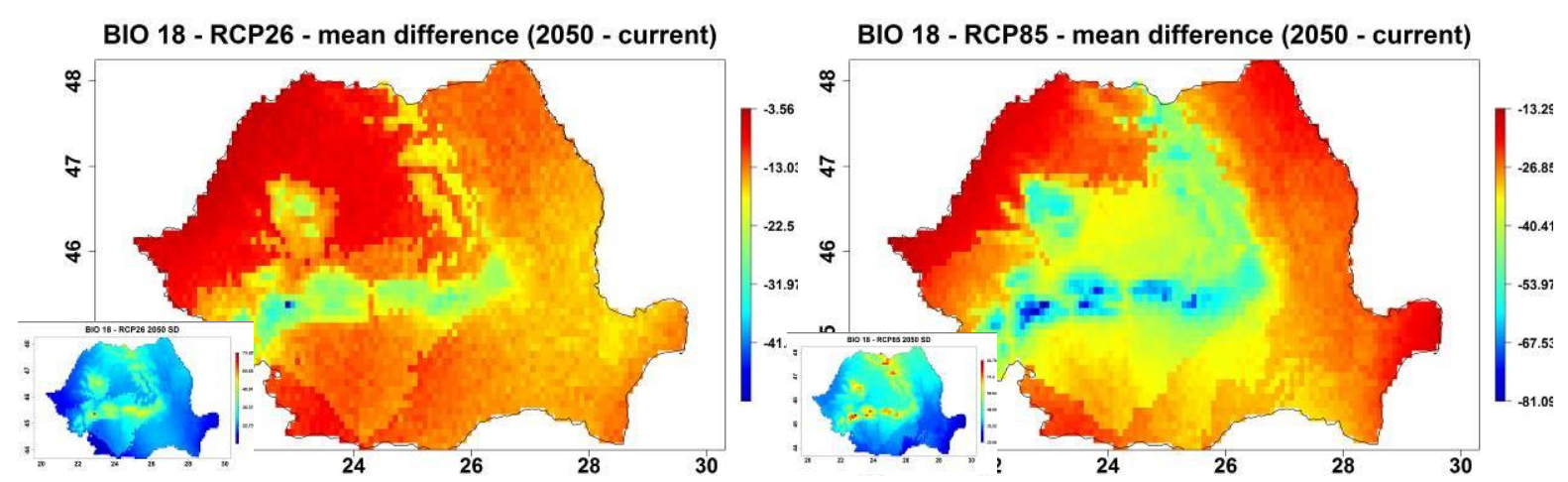

Fig. 20: Average GCM difference between predicted and current values for the precipitation of the warmest quarter in 2050 - RCP26 (left), RCP85 (right). Standard deviations are presented in the lower left corner for both cases (SD values between $20.61-73.21 \mathrm{~mm}$ for RCP26, SD between $20.96-83.72 \mathrm{~mm}$ for RCP85).

As this is a more stable quarter, we can state that the country average precipitation in summer months (June, July, August) is predicted to decrease in 65 of the 88 GCM-RCP-year scenarios. The highest country average decrease is predicted by the $h d$ GCM for RCP85 in 2070 $(-124 \mathrm{~mm})$. The highest increase is indicated by the $\mathrm{mg}$ GCM for RCP60 in $2070(+24.2 \mathrm{~mm})$. This GCM $(m g)$ is the one indicating the highest increase in summer precipitations in most GCM-RCP-year scenarios, while $h d$ indicates the highest decrease in summer precipitations in most combinations.

With regard to spatial variation (Fig. 20, large maps), the regions with higher altitudes are predicted to lose more precipitation than lower altitudes (and they are also the regions with higher disagreement between models). Disagreement between models is high in general, and higher for the areas with higher altitudes (Fig. 20, small maps).

\section{BIO19 - Precipitation of Coldest Quarter (units: mm)}

The coldest quarter (winter) has cumulated rainfall values between 64 and $204 \mathrm{~mm}$ at this resolution.

Only 14 of the total 88 combinations of GCM, RCP and year predict a country average decrease in precipitations for winter (Tab. 21), but it is difficult to say whether the starting month remains constant in all situations (while it most likely remains December, it is possible that in rare occasions it may shift to other months - i.e. January). Even so, this is a meaningful variable for many species, and the country average is expected to vary between $-14.4 \mathrm{~mm}$ (ip GCM, RCP85, 2050) and $+28.5 \mathrm{~mm}$ (mg GCM, RCP85, 2070). The ip GCM is typically the one indicating the highest decrease in precipitations, while the $h d$ model indicates the highest increase in precipitations.

Winter precipitations are expected to increase more in the north of Romania and in the mountains, and less in the south (where they may decrease) - Fig. 21, large maps. Model disagreement is rather high overall, and higher in the south of Romania for both case studies presented - Fig. 21, small maps. 
Table 21: Country average (and standard deviation) of predicted differences for each GCM-RCP-year combination (units: $\mathbf{m m}$ ); minimum and maximum values for each row are highlighted.

\begin{tabular}{|c|c|c|c|c|c|c|c|c|c|c|c|c|}
\hline Year & RCP & bc & cc & gs & hd & he & ip & mc & mg & mi & $\mathbf{m r}$ & no \\
\hline \multirow[t]{8}{*}{2050} & RCP26 & 8.4 & 4.6 & -0.7 & 23.4 & 10.4 & -7.0 & 0.1 & 2.1 & 2.7 & 4.8 & 2.0 \\
\hline & SD & 2.8 & 1.8 & 2.5 & 4.4 & 2.9 & 8.9 & 2.6 & 5.2 & 5.0 & 4.1 & 1.7 \\
\hline & RCP45 & 1.4 & 10.5 & 1.1 & 10.6 & 5.3 & -8.5 & 9.8 & 15.1 & 20.2 & 2.8 & 3.4 \\
\hline & SD & 3.6 & 2.4 & 1.8 & 4.5 & 4.1 & 5.0 & 4.1 & 5.0 & 6.7 & 4.0 & 4.6 \\
\hline & RCP60 & 2.3 & 7.4 & 0.2 & 8.0 & 3.3 & -0.4 & 7.8 & -5.1 & 11.5 & 9.1 & 3.6 \\
\hline & $\mathrm{SD}$ & 1.4 & 2.9 & 2.0 & 3.3 & 7.7 & 4.2 & 3.6 & 6.4 & 6.0 & 3.8 & 2.2 \\
\hline & RCP85 & 12.4 & 2.1 & 4.8 & 7.8 & 8.0 & -14.4 & 10.2 & 11.2 & 1.5 & 1.1 & 12.5 \\
\hline & SD & 3.0 & 2.0 & 4.5 & 3.7 & 5.5 & 6.4 & 3.3 & 3.6 & 6.9 & 3.3 & 4.4 \\
\hline \multirow[t]{8}{*}{2070} & $\mathrm{RCP} 26$ & 9.3 & 2.6 & 3.6 & 16.4 & 9.1 & -7.4 & 3.6 & 0.2 & 9.3 & 8.0 & -3.6 \\
\hline & SD & 2.0 & 3.2 & 2.1 & 3.8 & 2.5 & 4.6 & 4.8 & 3.3 & 6.8 & 4.1 & 2.4 \\
\hline & RCP45 & -3.1 & 4.3 & 0.5 & 17.6 & 16.5 & -6.6 & 9.6 & 3.9 & 4.2 & 4.8 & 5.4 \\
\hline & SD & 1.6 & 2.0 & 2.9 & 6.0 & 6.4 & 6.7 & 6.5 & 4.8 & 4.7 & 8.0 & 1.9 \\
\hline & RCP60 & 4.5 & 9.0 & 2.4 & 25.6 & 10.1 & -7.1 & 5.9 & -0.7 & 7.3 & 13.4 & 9.0 \\
\hline & SD & 2.3 & 3.1 & 1.6 & 8.0 & 5.5 & 9.8 & 5.0 & 2.9 & 4.9 & 4.5 & 4.4 \\
\hline & RCP85 & 20.0 & 9.8 & 1.1 & 20.5 & 17.1 & -11.9 & 10.1 & 28.5 & 22.6 & -4.2 & 9.7 \\
\hline & $\mathrm{SD}$ & 3.2 & 2.7 & 3.7 & 8.0 & 6.4 & 7.4 & 4.6 & 12.1 & 7.7 & 3.7 & 1.6 \\
\hline
\end{tabular}

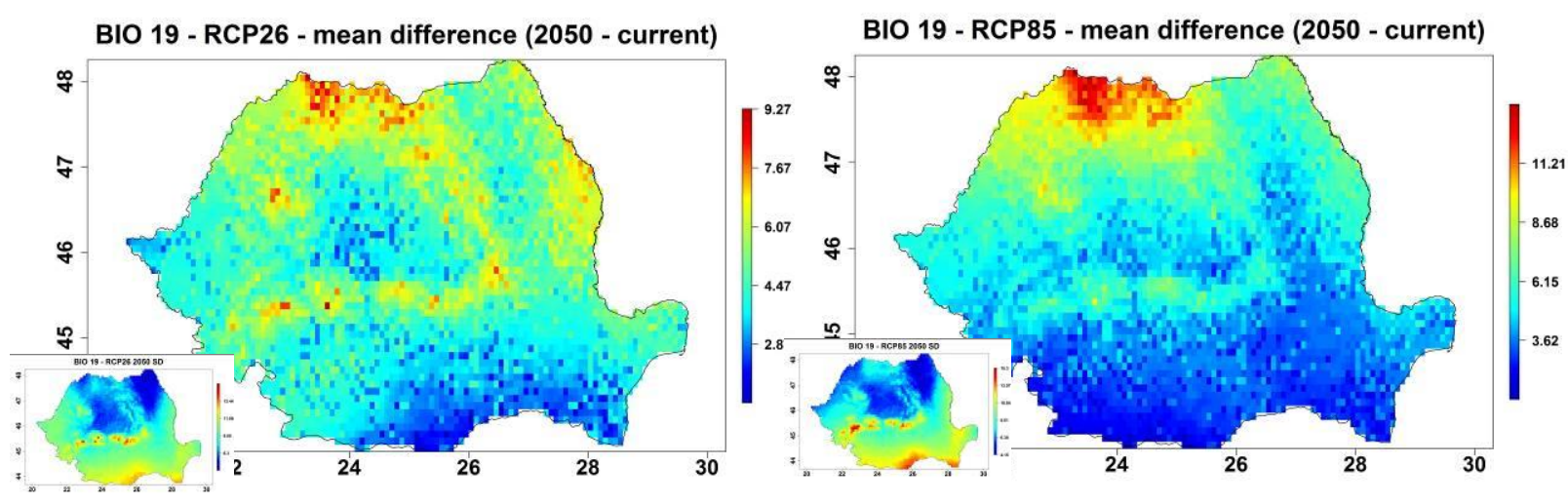

Fig. 21: Average GCM difference between predicted and current values for the precipitation of the coldest quarter in 2050 - RCP26 (left), RCP85 (right). Standard deviations are presented in the lower left corner for both cases (SD values between 5.89-15.74 mm for RCP26, SD between 4.15-15.25 mm for RCP85).

\section{Discussion}

The model indicating the highest country average mean annual temperature increase (BIO1) is the $\boldsymbol{h d}$ model. The $h d$ model also predicts the highest country average increase in maximum temperature of warmest month (BIO5), mean temperature of warmest quarter (BIO10), mean temperature of driest quarter (BIO9) and ranks high in most temperature related variables (mean diurnal range - BIO2, minimum temperature of coldest month - BIO6, temperature annual range - BIO7, mean temperature of coldest quarter - BIO11). It is very peculiar to find this model as the most conservative in relation to the country average increase in mean temperature of wettest quarter (BIO8). This finding suggests that the wettest quarter shifts for large areas of Romania, from approximately summer (May to July) to a cooler period 
(autumn or spring most likely). In relation to precipitations, it is one of the more pessimistic models, with 6 of the 8 yearly combinations of GCM, RCP and year (averages for Romania) being negative for $\mathrm{BIO} 12$ (annual precipitation), and 3 of these are the worst top 3 predicted decreases for precipitations in Romania (RCP85 for 2050 and 2070, and RCP45 for 2070). The $85 \mathrm{RCP}$ scenario is the worst country average decrease for many precipitation variables (BIO14 precipitation of driest month, BIO16 - precipitation of wettest quarter (! even if this changes from summer to spring as stated), BIO17 - precipitation of driest quarter, BIO18 - precipitation of warmest quarter). It is interesting to note that this model is among the most optimistic in relation to the country average winter precipitations (BIO19, precipitation of the coldest quarter). Usually, the he model predictions are similar to the $h d$ model, but less extreme, i.e. a more moderate model. The variable for which they are most dissimilar is BIO17 (precipitations of driest quarter), where $h d$ typically predicts a drier future, and he is among the most optimistic models (less dry future).

The lowest country average temperature increase is predicted by the $\boldsymbol{m g}$ model. It also predicts a decrease in the country averages of mean diurnal range (BIO2) and temperature seasonality (BIO4) - with the exception of the most optimistic RCP scenarios (26 and 45) for 2050, where it predicts an increase in BIO4. It is also the most optimistic scenario in relation to mean temperature of warmest quarter (BIO10), predicting the lowest country average increase in summer months. It is overall an optimistic scenario, with few exceptions (i.e. higher predicted values for RCP85 in the case of some variables such as BIO9 - mean temperature of driest quarter). In relation to precipitations, it is also one of the optimistic models, predicting a country average increase in most combinations of GCM-RCP-year and precipitation variable (only 12 of 64 combinations are negative, and $m g$ is never in the top 5 models in relation to reductions of precipitation variables). The $m g$ can be used as a model predicting less change for temperatures in Romania, with a slightly more humid climate.

The ip model stands out in relation to the coldest months predictions. It is among the few to predict a decrease in country averages for winter precipitations (BIO19 - precipitation of coldest quarter), and among the ones to predict the highest increase of country averages for winter temperatures (BIO6 - minimum temperature of coldest month, BIOI1 - mean temperature of coldest quarter). In relation to summer temperatures, it is a moderate model, with country average values far from minimum or maximum values predicted by other GCMs (BIO5 maximum temperature of warmest month, BIO10 - mean temperature of warmest quarter). Even in relation to BIOI (annual mean temperature) it can be considered a moderate model, with maybe the exception of RCP85 predictions which are higher (especially in 2070). The ip model is one of the most extreme predicting a country average decrease for mean diurnal range (BIO2) - between $0.3-0.82^{\mathrm{O}} \mathrm{C}$ average for Romanian territory (extreme country average values of the 8 combinations between RCP and year). It also predicts a country average decrease in temperature annual range $(B I O 7)$ - between $1.4^{\mathrm{O}}$ and $3.1^{\mathrm{O}} \mathrm{C}$ (extreme country average values of the 8 combinations between RCP and year). For annual precipitation (BIO12), it is a moderate model, with average country values ranging between $-20 \mathrm{~mm}$ and $+20 \mathrm{~mm}$ for all RCP and year combinations (excepting the 2070 RCP85 prediction, indicating a $-62.6 \mathrm{~mm}$ country average).

The gs model stands out in relation to precipitation variables (BIO 13 - precipitation of wettest month, BIO14 - precipitation of driest month). It is the model predicting some of the highest decreases for country average precipitation of wettest month (BIO13) - with values 
between $-18 \mathrm{~mm}$ and $-1.9 \mathrm{~mm}$ (depending on RCP and year combination). It is also among the few to predict a very mild increase of country average precipitations for driest month (BIO14), (values between $0 \mathrm{~mm}$ and $+1.2 \mathrm{~mm}$ ). This has evident implications for country average of BIO15 (precipitation seasonality), which is predicted to decrease by all combinations of this model. In relation to temperature, it is one of the more optimistic models, predicting a lower increase of annual mean temperature (BIO1). With the exception of RCP85 scenarios, it rarely predicts very high country average values for any temperature variable.

Maybe the most balanced model for all variables is the $c c$ model. It predicts annual mean temperature (BIO1) country average increases between $+1.6^{\circ} \mathrm{C}$ and $+3.8^{\circ} \mathrm{C}$ (extreme predictions by GCM-RCP-year combinations are $+0.9{ }^{\circ} \mathrm{C}$ and $+6.3{ }^{\circ} \mathrm{C}$ ), accompanied by a predicted change in annual precipitation ranging from a country average of $-28.1 \mathrm{~mm}$ to $+14.3 \mathrm{~mm}$ (compared to extreme predictions $-101.8 \mathrm{~mm}$ and $+98.2 \mathrm{~mm}$ ). It is a bit more optimistic in relation to BIO6 (minimum temperature of coldest month), where it is among the models predicting the lowest increase, and also in relation to BIO11 (mean temperature of coldest quarter).

Another moderate model is the $\boldsymbol{b c}$ model. For precipitations, this model is never in the top 5 extreme predictions (positive or negative). It predicts a moderate to slightly pessimistic future for precipitations (sporadically it predicts important changes, mostly negative - the positive ones are usually for RCP26, the optimistic greenhouse emissions scenario). For temperatures it is a moderate scenario, slightly optimistic (only 14 of 56 year-RCP combinations for direct temperature variables $(B I O 1, B I O 5, B I O 6, B I O 8, B I O 9, B I O 10, B I O 11)$ are in the upper half of all GCM-RCP-year predictions - i.e. predictions indicating a high country average temperature increase).

Similarly, the no model is rather optimistic - moderate for temperature variables (it rarely predicts extreme temperature increase outside the RCP85 scenario). For precipitations it is rather moderate - pessimistic (typically predicting country average decrease - with the exception of optimistic RCP26 scenarios, where it predicts small country average increases; it never predicts extreme country average decrease or increase).

The $\boldsymbol{m} \boldsymbol{r}$ model is of interest for many of the derived temperature variables. It predicts some of the higher decreases of country average for BIO3 (isothermality), even if the predicted average country change is small. It also predicts among the highest increases of country average for BIO4 (temperature seasonality) suggesting a higher variation of temperature throughout the year. It is also among the models indicating the highest increase of country average for $\mathrm{BIO}$ (temperature annual range). In relation to direct temperature variables, it is a moderate to pessimistic model (while the country average predicted values are rarely the most extreme, they are constantly in the higher prediction half of all GCM-RCP-year combinations considered). For precipitation variables, it is a rather optimistic model, predicting either moderate country average increases or small decreases for each variable, some exceptions being observed in the RCP85 scenarios.

The $\boldsymbol{m} \boldsymbol{c}$ model is moderate to pessimistic about temperature increase (with rather rare exceptions, it predicts above-average increases in country average temperature for Romania). It is however one of the most optimistic models about precipitation, as it often indicates a country average increase. Even though in few cases it predicts a decrease for country average of precipitation variables, the decrease is very small (maximum predicted decrease is $-2.3 \mathrm{~mm}$ ). The $\mathbf{m i}$ model is rather similar to $m c$ in relation to the predicted increase of temperatures (it is also a 
rather pessimistic model). For precipitation, the $m i$ model is one of the most variable, with a large amplitude of country average predictions. It is advisable to check each case in part if it is used.

\section{Conclusions}

Overall, while for temperature variables there is a general consensus as to the increase of temperatures for Romania for all combinations of GCM, RCP and year and spatial distribution of data, for precipitations the trends are not very clear (nor in relation to the GCM-RCP-year combinations, nor in relation to spatial distribution). An exception is probably the RCP85 scenario, which causes most GCMs to predict a decrease in precipitation (some a rather pronounced one). Aside from this, there is little consensus between models for precipitations, even for the same year and RCP. A positive statement that can be made is that predicted variation for country average precipitation is in many cases rather small, and there is no clear pattern emerging in regards to a decrease of precipitation amount in Romania (except for the RCP85 scenario). Variables based on wettest quarter (BIO8 - mean temperature of wettest quarter, BIO16 - precipitation of wettest quarter) need to be handled with care, as wettest quarter of the year may change significantly in some scenarios (i.e. from warm months to cooler months).

As all the bioclim variables are averages (monthly, quarterly or yearly averages), they say little about the daily variability of precipitations. Recent studies prove that, on average, in about 12 days, any location on Earth receives half of the yearly precipitation [9]. This precipitation asymmetry is predicted to increase with climate change. Models for such situations need to be found from other sources.

With most GCMs predicting a warmer future, it is likely that species loving warm conditions will expand, generally from the south to the north of Romania, and from low altitudes to high altitudes. The species for which precipitation variables are the most important in the niche models are more difficult to predict in the future. For such species, the variability between GCM predictions is at least as important as the variability between RCP predictions. This is often the case also for species for which temperature variables are the most important, so we can state that is important in general to choose GCMs with full knowledge of their predicted effects for any analysis related to climate change. The tables with country averages and standard deviations for the 19 bioclim variables in 88 GCM-RCP-year combinations allow a case-by-case consideration for including a variable in a species distribution model, making it possible to select a GCM which expresses high, low or moderate variation in Romania for that variable. These tables also allow a comparison between the change predicted by various combinations of GCM and RCP for all the 19 bioclim variables on the Romanian territory. 19 Biodivers

Acknowledgement: IAS acknowledges funding from the Romanian Ministry of Research - program PN16

\section{REFERENCES}

1. Bivand, R., Keitt, T., Rowlingson, B., 2016, rgdal: Bindings for the Geospatial Data Abstraction Library. Retrieved from https://cran.r-project.org/package=rgdal 
2. Hijmans, R. J., Cameron, S. E., Parra, J. L., Jones, P. G., Jarvis, A., 2005, Very high resolution interpolated climate surfaces for global land areas, International Journal of Climatology, 25(15): 1965-1978. doi:10.1002/joc. 1276

3. Hijmans, R. J., van Etten, J., 2012, raster: Geographic analysis and modeling with raster data. Retrieved from http://cran.r-project.org/package=raster

4. Koo, K. A., Park, S. U., Kong, W. S., Hong, S., Jang, I., Seo, C., 2017, Potential climate change effects on tree distributions in the Korean Peninsula: Understanding model \& climate uncertainties, Ecological Modelling, 353: 17-27. doi:10.1016/j.ecolmodel.2016.10.007

5. Magrach, A., Ghazoul, J., 2015, Climate and pest-driven geographic shifts in global coffee production: Implications for forest cover, biodiversity and carbon storage, PLOS ONE, 10(7): 1-15. doi:10.1371/journal.pone.0133071

6. O'Donnell, M. S., Ignizio, D. A., 2012, Bioclimatic Predictors for Supporting Ecological Applications in the Conterminous United States, U.S Geological Survey Data Series 691, : 10. doi:10.1016/j.mimet.2011.04.001

7. Oliveira, S. V. de, Romero-Alvarez, D., Martins, T. F., Santos, J. P. dos, Labruna, M. B., Gazeta, G. S., Escobar, L. E., Gurgel-Gonçalves, R., 2017, Amblyomma ticks and future climate: Range contraction due to climate warming, Acta Tropica, 176(June): 340-348. doi:10.1016/j.actatropica.2017.07.033

8. Osorio-Arce M M y Segura-Correa J C, 2014, IPCC Fifth Assessment Synthesis Report-Climate Change 2014 Synthesis Report, Livestock Research for Rural Development, : pages: 167. doi:citeulike-articleid: 13416115

9. Pendergrass, A. G., Knutti, R., 2018, The uneven nature of daily precipitation and its change, Geophysical Research Letters, : 1-9. doi:10.1029/2018GL080298

10. R, 2010, R: A language and environment for statistical computing, R Foundation for Statistical Computing, Vienna, Austria. Retrieved from http://www.r-project.org/

11. Raghunathan, N., François, L., Dury, M., Hambuckers, A., 2018, Contrasting climate risks predicted by dynamic vegetation and ecological niche-based models applied to tree species in the Brazilian Atlantic Forest, Regional Environmental Change. doi:10.1007/s10113-018-1405-8

12. Sun, Y., Bronnimann, O., Roderick, G. K., Poltavsky, A., Lommen, S. T. E., Müller-Schärer, H., 2017, Climatic suitability ranking of biological control candidates: A biogeographic approach for ragweed management in Europe, Ecosphere, 8(4). doi:10.1002/ecs2.1731

13. Walker, A., 2017, openxlsx: Read, Write and Edit XLSX Files. Retrieved from https://cran.rproject.org/package $=$ openxlsx

\title{
O INTERPRETARE A PREDICTIIILOR GENERATE DE MAI MULTE MODELE PENTRU VARIABILELE BIOCLIM ÎN ROMÂNIA
}

(Rezumat)

\begin{abstract}
Schimbările climatice reprezintă una dintre cele mai mare provocări ale secolului. Deoarece pentru teritoriul României există mai multe modele climatice, fiecare simulând un număr de scenarii posibile de emisii de gaze de seră, este foarte dificil de sintetizat impacturile prevăzute. Articolul analizează rezultatele unei părți din setul de date Worldclim, anume cele 19 variabile bioclim, pentru 11 Modele de Circulație Generală (GCM), 4 RCP-uri (scenarii de emisie a gazelor de seră) și 2 ani $(2050,2070)$, la o rezoluție de 5 arc minute $(\sim 10 \mathrm{~km})$. Aceste 19 variabile au fost concepute pentru a fi relevante referitor la fiziologia speciilor din diferite regnuri, și sunt în prezent folosite des în literatura de specialitate, pentru parametrizarea modelelor de distribuție a speciilor. Pentru a putea face alegeri bazate pe informații în parametrizarea modelelor (a simulărilor referitoare la schimbările viitoare ale nișelor speciilor), este nevoie de o interpretare a variabilității în viitor al fiecărui factor bioclim pentru fiecare combinație de GCM, an și RCP. Chiar dacă importanța GCM-urilor variază pentru fiecare factor bioclim și fiecare combinație de an și scenariu RCP, se pot extrage unele caracteristici generale pentru fiecare GCM în parte. Pentru teritoriul României, modelul $h d$ (HadGEM2-AO) poate fi considerat per total ca fiind pesimist cu privire la variabilele de temperatură și precipitații (prognozând o creștere puternică a temperaturii, și o scădere puternică a
\end{abstract}


precipitațiilor). Modelul $m g$ (MRI-CGCM3) poate fi privit ca fiind un model optimist cu privire la creșterea temperaturii (simulând o încălzire mai redusă), dar și în ceea ce privește precipitațiile (simulând cantităţi mai ridicate de precipitaţii). Modelul $m i$ (MIROC-ESM-CHEM) de asemenea prognozează un viitor mai umed în România, dar cu o creștere mai ridicată a temperaturii. Modelul ip (IPSL-CM5A-LR) prognozează cea mai ridicată creștere a temperaturii în lunile reci din România, dar și ierni mai uscate, și o variabilitate mai redusă a temperaturii (lunară și anuală). Un model mai moderat pentru țara noastră este $c c$ (CCSM4), ce poate fi folosit ca model echilibrat (este optimist doar în ceea ce privește temperaturile din sezonul rece, unde prognozează cea mai redusă creștere). Per total, pentru variabilele legate de temperatură, există un consens general (creșterea temperaturilor pentru toate combinațiile de GCM, RCP și an). Cu privire la precipitații, tendințele nu sunt foarte clare. O excepție o reprezintă scenariul RCP85, pentru care majoritatea GCM-urilor prognozează o scădere a precipitațiilor, dar chiar și pentru acest scenariu există modele care indică o creștere a acestora.

Received: 13.11.2018; Accepted: 1.12.2018. 